\title{
Mallotus philippensis (Lam.) Müll. Arg.: A review on its pharmacology and phytochemistry
}

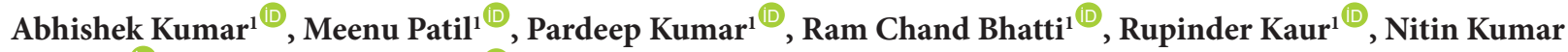 \\ Sharma $^{2}{ }^{\mathbb{D}}$, Anand Narain Singh ${ }^{*} \mathbb{D}$ \\ ${ }^{1}$ Department of Botany, Panjab University, Chandigarh-160014, India \\ ${ }^{2}$ Department of Botany, Govt. College Amb, Una, Himachal Pradesh-177203, India
}

\section{A R T I C L E I N F O}

Article Type:

Review

\section{Article History:}

Received: 21 September 2019

Accepted: 4 November 2019

\section{Keywords:}

Kamala tree

Mallotus philippensis

Ethnomedicinal uses

Pharmacology

Phytochemistry

Rottlerin

\begin{abstract}
A B S T R A C T
Kamala tree (Mallotus philippensis) is traditionally used by different ethnic groups to treat a variety of diseases and health ailments. However, these traditional uses need to be scientifically investigated and validated in order to develop drugs from this tree. Therefore, the present article is aimed to review the scientifically validated knowledge on the pharmacology and phytochemistry of the tree. To accomplish this, we extensively surveyed the available databases like Scopus, Web of Science, Google Scholar, ScienceDirect, NCBI including PubMed and PubChem etc. by using keywords 'Mallotus philippensis', 'Mallotus phillippinensis' and 'Mallotus philippinensis'. Our results indicated that the tree possesses more than 50 different types of important phytochemicals of natural origin. The wide array of phytochemicals possesses fascinating biological activities like anthelmintic, antibacterial, anti-inflammatory, anti-oxidant, anti-cancerous, anti-tuberculosis, anti-parasitic, analgesic, anti-urolithiatic and anti-viral activities. Thus, pharmacological activities and isolation of active phytochemicals make the tree a promising candidate for drug discovery. However, the pharmacological activities such as antibacterial and anti-oxidant activities are often tested with crude extracts and in vitro rudimentary methods that can be sometimes misleading and non-specific. Thus, more sophisticated techniques may be applied for isolation of active chemicals and elucidating their mechanism of actions.
\end{abstract}

Implication for health policy/practice/research/medical education:

This review article presented the progress of scientific investigations and validation of traditional uses of the Kamala tree (Mallotus philippensis). Antimicrobial properties of the tree are extensively investigated whereas other pharmacological properties like anthelminthic, anti-viral, anti-urolithiatic etc, still need to be investigated. Specifically, the active phytochemicals such as Rottlerin and Mallotophilippens can be novel drugs for the treatment of cancer and tuberculosis in future.

Please cite this paper as: Kumar A, Patil M, Kumar P, Bhatti RC, Kaur R, Sharma NK, Singh AN. Mallotus philippensis (Lam.) Müll. Arg.: A review on its pharmacology and phytochemistry. J Herbmed Pharmacol. 2021;10(1):31-50. doi: 10.34172/jhp.2021.03.

\section{Introduction}

Indigenous people and local ethnic communities have learned and developed knowledge to use specific plants for various health disorders and ailments from pre-historic times. These practices are still continued and common in remote areas of the Indian subcontinent where no or few health facilities are available. This ethnomedicinal system has provided the clue for discovering many therapeutically useful compounds that have been now developed into important drugs. For instance, two modern anti-malarial drugs quinine and artemisinin have been developed from indigenous knowledge from the Amazon basin and China respectively, where local people use them for treating fevers. Furthermore, about $65-75 \%$ of modern drugs recommended for cancer and other infectious disease have been directly or indirectly derived from traditional knowledge (1). More recently, two anti-diabetic drug formulations (BGR-34 and IME9) were developed in India that are based on traditional medicinal practices of various local communities of the country. Thus, the ethnomedicinal system of the various ethnic groups has provided indigenous knowledge that leads to the discovery of therapeutically useful compounds from plants to modern science. Traditional knowledge 
of a particular geographical area can act as a modulator for further cutting-edge research in modern science. The combination of traditional and modern knowledge together may produce better results for human beings.

The medicinal properties of Kamala are remarked in ancient Indian literature like Charaka Samhita, Sushruta Samhita, Indian Materia Medica and Indusyunic Medicine (2-4). Earliest medicinal systems like the Ayurveda and the Yunani also advocate its usage as alexiteric, anthelmintic, appetiser, bitter, carminative, cooling, purgative, styptic and vulnerary (5-7). Some of these medicinal properties of this species are already transformed into commercially available drug formulations like Krimighatni Bati and Krimikuthar Rasa for intestinal worms and Roghan Kameela and Zimad Jarb for dermatological disorders (8). However, these traditional uses can be unrealistic or superfluous, therefore, a scientific authentication and validation of these properties are necessary in order to develop effective modern drugs. The pharmacological properties and isolation of active chemical compounds from this tree have progressed considerably during the past few decades. Thus, a variety of important phytochemical compounds such as cardenolides, flavonoids, tannins, fatty acids, chalcone and phloroglucinol derivatives have been isolated and characterised from this plant (9). These important active chemicals possess interesting pharmacological activities like anti-cancer, anthelmintic, anti-fertility, antimicrobial, anti-oxidant, anti-inflammatory and many others are expected to be discovered soon (10).

Despite recent advancement in pharmacological science, we have limited information about the validation of traditional medicinal usage of this tree. Though, previous review articles have attempted to document and analyse information about the species, complete and updated information about the progress and gaps in the field is still lacking (10-13). Therefore, the present review article aims to answer the following questions: 1) How many biological activities from this plant have been tested and validated so far? 2) What are the different active phytochemicals that have been isolated and characterised from this particular species? 3) What are the observed progress and gaps in our knowledge about the pharmacology and phytochemistry of this species? This has been achieved by extensively surveying available databases along with unpublished grey literature in terms of dissertations and theses. Further, we have included possible mechanisms and patents wherever possible. Yet, we do not pretend to be complete in our review, as collecting all the literature is a tough task and some studies seemed to be beyond the scope of this review article, but surely, it will be useful for future research on the same tree.

\section{Methods}

In order to get more and more information on the same tree, we have extensively searched available databases like Scopus (Mallotus AND phili*), Web of Science (Mallotus AND phili*), Google Scholar (allintitle: "Mallotus philippensis" OR "Mallotus philippinensis"), Science Direct ("Mallotus philippensis" OR "Mallotus philippinensis"), PubMed (Mallotus AND phili*). We got 245 articles from Scopus, 115 articles from Web of Science, 131 articles from Google Scholar, 313 articles from Science Direct, 54 articles from PubMed. Thus, in total, we got 858 articles through database searching and 19 additional records were found through other sources including published books, unpublished theses and patents. After removing duplicate, insignificant and inappropriate studies, finally, 110 articles were included for the preparation of the present article. Some articles including antibacterial studies without minimum inhibitory concentration (MIC), anti-oxidant assays employing 2, 2-diphenyl-1-picrylhydrazyl (DPPH) and other in vitro assays have been discarded. However, some studies that seemed relevant were included even if they did not meet the above criteria, as these studies provided indications for further work on the subject. The chemical structures presented in the manuscript were prepared from previously published studies using the ChemOffice ${ }^{\circledR}$ (16.0) program available from PerkinElmer, Inc. All other figures were prepared using the $R$ programming language (14).

\section{Socio-economic importance}

Natural dyes play an important role in the livelihood of local and rural people. For example, in Bhutan, rural people cultivate dye-yielding plants, prepare dye and earn money by selling the dye (15). The glands of ripened fruits of this tree yield a yellow to orange-red coloured dye, called Kamala dye (16-18). Fresh fruits are known to yield about $1.4 \%-3.7 \%$ red powder containing pigment Rottlerin (19). A patent has also been granted for describing the method of extraction of the dye from the fruit-pericarp of the tree containing readily water-soluble rottlerin (20). The red dye obtained from the tree is frequently used for preparing traditional Bhutanese fabrics and colouring silk clothes (15). This dye along with a mordant (Alum) is used for dyeing silk and wool $(17,19)$. This dye is believed to be superior for woollen and silk fabrics (21).

The Kamala powder is also used as a dyestuff in food $(17,21)$. The active compounds of the dye, rottlerin and its penta-potassium derivatives are employed for colouring foodstuffs, juices and other beverages (22). Apart from colouring soaps, oils and ice creams (17), it is also employed as an anti-oxidant for ghee and vegetable oils $(17,19)$. The powdered dye is widely used in perfume, leather and textile industry. The dyestuff finds applications in paintings and decorating wooden crafts especially by Bokshas (an indigenous community found in the Western region of Himalayas) (21). In chromotherapy, the dye is 
used for body adornment (21). In addition to fruit powder, the seed oil is used in painting and varnishing works (22). The oil is also used as a substitute for Tung oil (Vernicia Lour., Euphorbiaceae) in the formulation of rapid drying paints, varnishes, hair fixers and ointments (16). Thus, the tree has several important non-medicinal uses also, which are important from a socio-economic point of view.

\section{Pharmacology}

As discussed in the previous section, the tree has the potential to cure a variety of diseases and health disorders as indicated by their traditional uses. Taking inspiration from these conventional uses, many researchers and in particular pharmacologists have tested and validated the medicinal potential of this plant with a scientific background. Therefore, in this section, an assessment of about 84 studies pertaining to different biological activities have been discussed. Also, the active compounds responsible for their activity and their mode of action have been discussed wherever available.

The distribution of these studies under different categories of biological activities suggests that antibacterial, anti-oxidant and anti-parasitic activities have been most frequently investigated and contributed to about $50 \%$ of the total pharmacological studies on this particular plant species (Figure 1).

Anthelmintic activity

As described in the previous section, fruits are exclusively used for helminthic infestations both for human beings as well as animals (23). Certainly, researchers have tested and evaluated its efficacy against several worms using various extracts. Most of the extracts have produced encouraging results for treating fascioliasis, filariasis and other intestinal worms. For example, alcoholic and ethereal extracts of fruits have shown anticestodal action against the dwarf tapeworm (Hymenolepis nana) and rat tapeworm (Hymenolepis diminuta), both in vitro and in vivo. The extracts also exhibited lethal efficacy against trematode, Fasciolopsis buski (24). Similarly, a resin isolated from ethanolic extracts of capsules possessed significant purgative and anthelmintic effects on tapeworms in the small intestine of rats. An oral dose of $120 \mathrm{mg} / \mathrm{kg}$ of the resin killed about $78 \%$ of tapeworms in albino rats (25). In another study, aqueous and alcoholic extracts of leaves caused inhibition of spontaneous motility of whole worm and the nerve-muscle preparation of nematode Setaria cervi Rudolphi, 1819 (Filarioidea), suggesting its potent anti-filarial activity. A MIC of $20 \mathrm{ng} / \mathrm{mL}$ for aqueous and $15 \mathrm{ng} / \mathrm{mL}$ for alcoholic extract was required for 6 hrs to cause $90 \%$ inhibition of this filarial worm (26). Recently, ethanolic extracts of fruits $(800 \mathrm{mg} / \mathrm{kg}$ twice a daily for 3 days) have shown anticestodal efficacy in cestode (Hymenolepis diminuta Rudolphi, 1819) intestinal infection model (27). Similarly, methanolic extract of fruits (10 and $20 \mathrm{mg} / \mathrm{mL}$ ) are reported to prevent dissemination of cestodal tapeworm (Echinococcus granulosus Batsch, 1786) by damaging the hooks and suckers and thus exhibiting significant scolicidal activity with almost no associated side effects (28).

Nevertheless, some authors have also questioned its efficacy at least against some worms and reported that it is ineffective as an anthelmintic. For example, alcoholic and ethereal extracts of fruits were not found effective against nematode (Ascaris lumbricoides Linnaeus, 1758) in vitro (24). It is also stated that Kamala is ineffective in reducing nematode ova per gram faeces in experimental goats, although it is purgative for these gastrointestinal

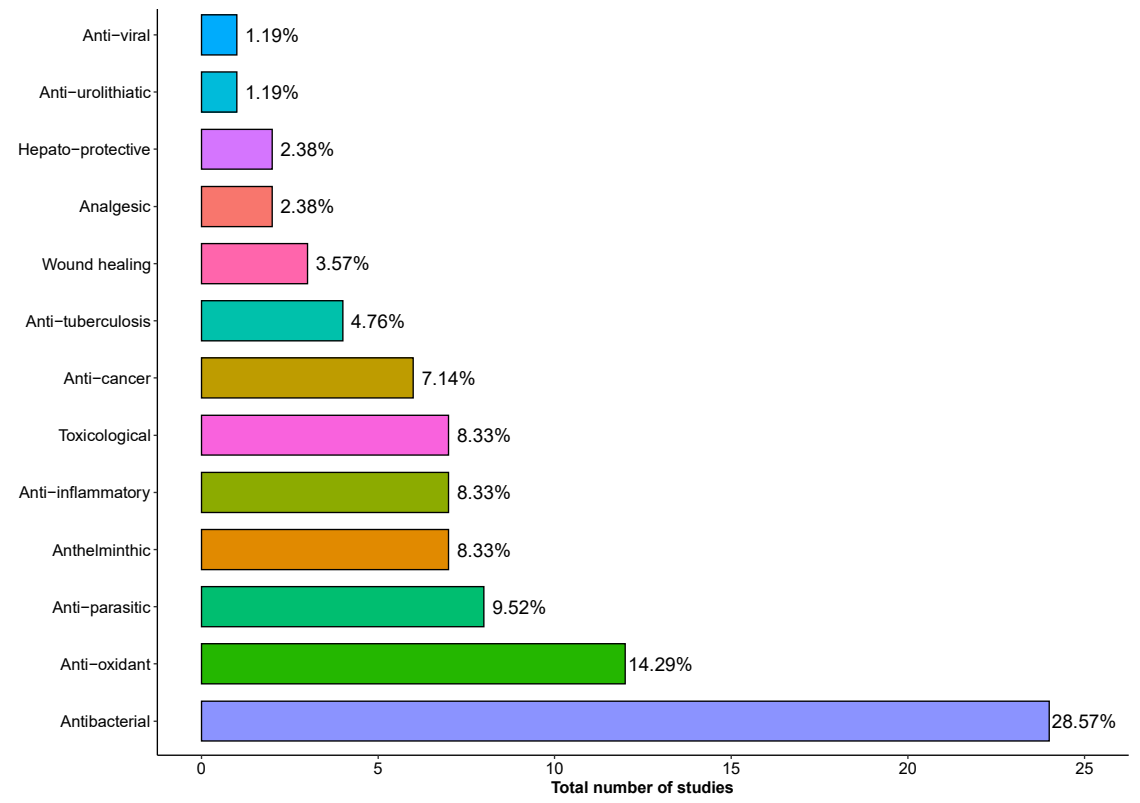

Figure 1. The distribution of studies under the different categories of biological activities. 
worms (29). Similarly, a single oral dose of the powdered fruits is not effective in eliminating direct life-cycle gastrointestinal nematodes in goats when compared with a single dose of fenbendazole.

Thus, the traditional anthelmintic potential of this plant is well-known, but its scientific validation is still in infancy and has been achieved only against few worms. Although some extracts of the plant have successfully evaluated against few cestodal worms, particularly active bio-chemical and mode of action is still not identified yet. In addition, reports for anthelmintic use for human beings are lacking.

\section{Antibacterial activity}

Bacteria are one of the most common disease-causing pathogens. However, they are evolving rapidly and available antibiotic drugs are continuously failing to control the bacterial infections especially in hospitals and rural areas. Thus, there is an urgent need to search for new potential sources of antibiotic drugs in order to treat multidrug-resistant (MDR) bacteria. Traditionally, bark juice is used among the Tharu, Magar, Chhetri, Newaris and Raute people of Nepal to treat various diseases and illnesses (diarrhoea, dysentery, etc.) caused by bacterial, fungal or viral pathogens which indicates its potential antibacterial and anti-viral properties (30). In our review, we have found that various extracts prepared from the tree are effective against more than 100 different strains of about 30 species of pathogenic bacteria. The strains of Staphylococcus aureus (21.19\%), Escherichia coli (9.32\%), Pseudomonas aeruginosa (8.47\%), Bacillus subtilis (7.63\%), Salmonella typhi (6.78\%), Helicobacter pylori (5.93\%) and Klebsiella pneumoniae (3.39\%) have been tested frequently for antibacterial activity and the extracts of this plant are most effective against Helicobacter pylori, Enterococcus faecalis and Staphylococcus aureus.

Among the active constituents, rottlerin and the Red compounds have been tested and found to be most effective. These studies including the applied extracts and methodologies are summarised in Table 1. Among methods used to test antibacterial activity, Disc diffusion and Agar well diffusion methods are most commonly used whereas broth dilution and agar dilution are the most frequent methods for determination of MIC. On the other hand, about $50 \%$ of total studies have not evaluated MIC and therefore efficacy of extracts is not clear. Such studies need to be revisited again and reconfirm the antibacterial potential of the particular extract. Further, only a few active chemicals such as rottlerin and Red compounds have been specifically evaluated for the antibacterial properties and the mechanisms of actions are still unknown for such compounds.

The use of various parts of the tree for treatment of skin disorders and infections can also be attributed to antibacterial, anti-parasitic, anti-tyrosinase and anti- melanogenic activity of its active constituents like rottlerin, mallotophilippen A and mallotophilippen B. Rottlerin exhibits anti-tyrosinase activity by mixed inhibition while mallotophilippen A and B exhibit non-competitive type of inhibition as revealed by Lineweaver-Burk plot. Rottlerin has high binding affinity to tyrosinase and induces a conformational change in the secondary and tertiary structure of tyrosinase (31). The anti-melanogenic potential of chloroform extracts of the fruits has been patented and used as a whitening agent in cosmetics (32). Moreover, a hair tonic prepared by extracting the bark of the tree in conventional solvents inhibits the transforming growth factor (TGF- $\beta$ ) preventing hair loss (33).

\section{Anti-oxidant activity}

Free radicals and reactive oxygen species are often considered deteriorative due to their oxidising effects. The chemical compounds that scavenge these reactive molecules and slow down oxidation process are termed as anti-oxidants. However, most of the molecules that exhibit anti-oxidant potential in vitro may not produce similar effects in vivo. Therefore, evaluation of antioxidant property of any molecule should include in vivo studies using the suitable model animal system rather than non-specific assays such as DPPH, reducing power assay and total anti-oxidant capacity (53). Despite nonspecificity of these in vitro methods, many authors have employed these methods to claim anti-oxidant activity of extracts prepared from the roots, stem-wood, stem bark, leaves and fruits of this particular tree $(54,55)$. For example, methanolic chloroform and aqueous extracts of leaves (41), ethanolic extracts of fruit glandular hairs (56), the acetonic and methanolic extracts of fruit and bark $(57,58)$ and an aqueous fraction of ethanolic extracts of stem-wood (55) have been claimed to exhibit remarkable anti-oxidant activity in reducing power assay, total antioxidant capacity and DPPH radical assay.

The aqueous fraction of ethanolic extracts of stemwood has Bergenin and 11-O-galloylbergenin that can be responsible for its strong anti-oxidant potential. The in vitro anti-oxidant activity assays show that 11-O-galloylbergenin is a more potent anti-oxidant as compared to Bergenin. Surprisingly, the anti-oxidant activity of 11-O-galloylbergenin is comparable with ascorbic acid and better than $\alpha$-tocopherol (55). Various extracts possess rottlerin as a chief component responsible for different pharmacological activities including the antioxidant potential. The anti-oxidant property of rottlerin is tested against the DPPH radical in vitro and confirmed against oxidative stress induced by 30 -min treatment of $\mathrm{H}_{2} \mathrm{O}_{2}$ or menadione in cultured cells. The levels of reactive oxygen species (ROS) were not only significantly lowered by $20 \mu \mathrm{M}$ rottlerin but also inhibited further ROS generation in HCF-7 cell lines (59). The maintenance of anti-oxidant environment by rottlerin may involve the 
Table 1. Antibacterial potential of Mallotus philippensis (Lam.) Müll. Arg. against different strains of Bacteria

\begin{tabular}{|c|c|c|c|c|}
\hline Bacteria & Part Used/Extract/Compounds & Methods & $\begin{array}{l}\text { MIC } \\
(\mathrm{mg} / \mathrm{mL})\end{array}$ & Source \\
\hline Aeromonas hydrophila (ATCC 7966) & Methanolic extracts of fruits & Disc diffusion and agar dilution & 18 & (34) \\
\hline Bacillus cereus & Methanolic extracts of seeds & Disc diffusion, agar-well diffusion and agar dilution & 6.25 & (35) \\
\hline Bacillus cereus (from HIV positive patient) & Silver nanoparticles (AgNPs) biosynthesized using leaf extracts & Disc diffusion & $\mathrm{NE}$ & (36) \\
\hline Bacillus cereus var. mycoides (ATCC 11778) & Dichloromethane and methanol $(1: 1, \mathrm{v} / \mathrm{v})$ extracts of fruit Glandular hairs & Agar dilution streak & NE & (37) \\
\hline Bacillus licheniformis & Aqueous extracts of leaves & Disc diffusion and agar-cup & $\mathrm{NE}$ & (38) \\
\hline Bacillus pumilus (ATCC 14884) & Dichloromethane and methanol $(1: 1, \mathrm{v} / \mathrm{v})$ extracts of fruit Glandular hairs & Agar dilution streak & $\mathrm{NE}$ & (37) \\
\hline Bacillus stearothermophilus & Methanolic extracts of the whole plant & Agar-well diffusion & 0.095 & (39) \\
\hline Bacillus subtilis & Ethyl acetate fractions of powdered whole plant & Agar-well diffusion & NE & (40) \\
\hline Bacillus subtilis & Methanolic Chloroform (1:1) and aqueous extracts of the whole plant & Disc diffusion & $\mathrm{NE}$ & (41) \\
\hline Bacillus subtilis & Chloroform: Methanol (1:1) and Chloroform: Methanol (8:2) fractions of bark & Cup-plate method & $\mathrm{NE}$ & (42) \\
\hline Bacillus subtilis & Methanol extracts prepared from Bark & Disc diffusion & NE & $(30,43)$ \\
\hline Bacillus subtilis & Methanolic extracts of fruits & Disc diffusion and agar dilution & 18 & (34) \\
\hline Bacillus subtilis (MTCC 441) & The acetone extracts of fruits & Agar-well diffusion & $\mathrm{NE}$ & (44) \\
\hline Bacillus subtilis BsSOP01 & Rottlerin & Antibacterial assay and broth dilution & 0.004 & (45) \\
\hline Bacillus subtilis (ATCC 6633) & Dichloromethane and methanol $(1: 1, v / v)$ extracts of fruit Glandular hairs & Agar dilution streak & $\mathrm{NE}$ & (37) \\
\hline Bordetella bronchiseptica (ATCC 4617) & Dichloromethane and methanol $(1: 1, \mathrm{v} / \mathrm{v})$ extracts of fruit Glandular hairs & Agar dilution streak & $\mathrm{NE}$ & (37) \\
\hline Corynebacterium bovis & Methanolic extracts of seeds & Disc diffusion, agar-well diffusion and agar dilution & 25 & (35) \\
\hline Enterobacter aerogens & Methanolic extracts of the whole plant & Agar-well diffusion & 0.11 & (39) \\
\hline Enterobacter aerogens & Methanolic Chloroform (1:1) and aqueous extracts of the whole plant & Disc diffusion & $\mathrm{NE}$ & (41) \\
\hline Enterococcus faecalis 12697 & Rottlerin & Antibacterial assay and broth dilution & 0.001 & (45) \\
\hline Enterococcus faecalis 13379 & Rottlerin & Antibacterial assay and broth dilution & 0.002 & (45) \\
\hline Escherichia coli & Ethanolic and aqueous extracts of fruits & Disc diffusion & $\mathrm{NE}$ & (46) \\
\hline Escherichia coli & Methanolic Chloroform extracts & Disc diffusion & $\mathrm{NE}$ & (41) \\
\hline Escherichia coli & Methanol extracts prepared from Bark & Disc diffusion assay & $\mathrm{NE}$ & (43) \\
\hline Escherichia coli & Chloroform and Methanol (8: 2) fractions of bark & Cup-plate method & $\mathrm{NE}$ & (42) \\
\hline Escherichia coli & Methanolic and Acetone extracts of fruits & Agar-well diffusion & NE & (47) \\
\hline Escherichia coli (ATCC 29922) & Methanolic extracts of seeds & Disc diffusion, agar-well diffusion and agar dilution & 12.5 & (35) \\
\hline Escherichia coli (MTCC 724) & The acetone extracts of fruits & Agar-well diffusion & $\mathrm{NE}$ & (44) \\
\hline Escherichia coli NCTC 10418 & Rottlerin & Antibacterial assay and broth dilution & 0.512 & (45) \\
\hline Escherichia coli NCTC 10418 & The Red compound & Antibacterial assay and broth dilution & 0.256 & (45) \\
\hline
\end{tabular}




\section{Bacteria}

Escherichia coli (ATCC 25922)

Escherichia coli (ATCC 35218)

Helicobacter pylori (Japanese Clarithromycin resistant)

Helicobacter pylori (Japanese Metronidazole resistant)

Helicobacter pylori (Japanese Metronidazole sensitive)

Helicobacter pylori (Pakistani Metronidazole-resistant)

Helicobacter pylori (Pakistani Metronidazole sensitive)

Helicobacter pylori ATCC 43504 (Clarithromycin resistant)

Helicobacter pylori ATCC 43504 (Metronidazole resistant)

Klebsiella pneumoniae

Klebsiella pneumoniae (ATCC 10031)

Klebsiella pneumoniae 342

Klebsiella pneumoniae 342

Micrococcus luteus

Micrococcus luteus (ATCC 9341)

Mycobacterium phlei

Mycobacterium smegmatis (MTCC 6 )

Mycobacterium smegmatis (MTCC 994)

Mycobacterium tuberculosis H37Ra

Mycobacterium tuberculosis H37Rv

Mycobacterium tuberculosis H37Rv

Mycobacterium tuberculosis H37Rv

Mycobacterium tuberculosis $\mathrm{H} 37 \mathrm{Rv}$

Mycobacterium tuberculosis H37Rv

Mycobacterium tuberculosis H37Rv

Mycobacterium tuberculosis H37Rv

Pasteurella multocida

Plesiomonas shigelloides (ATCC 14029)

Proteus mirabilis

Proteus sp. P10830

\section{Part Used/Extract/Compounds}

Methanolic extracts of fruits

Methanolic extracts of fruits

Ethanol extracts of Fruit hairs

Ethanol extracts of Fruit hairs

Ethanol extracts of Fruit hairs

Ethanol extracts of Fruit hairs

Ethanol extracts of Fruit hairs

Ethanol extracts of Fruit hairs

thanol extracts of Fruit hairs

Chloroform: Methanol (1:1) and Chloroform: Methanol (8:2 ratios) fractions of bark

Dichloromethane and methanol $(1: 1, \mathrm{v} / \mathrm{v})$ extracts of fruit Glandular hairs

Rottlerin

The Red compound

Methanolic extracts of the whole plant

Dichloromethane and methanol $(1: 1, \mathrm{v} / \mathrm{v})$ extracts of fruit Glandular hairs

Methanolic extracts of Bark

Ethyl acetate fraction of ethanolic extracts of leaves

Ethyl acetate fraction of ethanolic extracts of leaves

Ethanolic extracts of leaves

Ethanolic extracts of leaves

Methanol: dichloromethane (1:1) extracts flowers

Mallotophilippen F

8-Cinnamoyl-2,2-dimethyl-7-hydroxy-5-methoxychromene

Rottlerin

Isorottlerin

Red compound (8-cinnamoyl-5,7-dihydroxy-2,2,6-trimethylchromene)

Methanolic extracts of seeds

Methanolic extracts of fruits

Methanolic extracts of the whole plant

Rottlerin

\section{Methods}

Disc diffusion and agar dilution method

Disc diffusion and agar dilution method

E-test method

E-test method

E-test method

E-test method

E-test method

E-test method

E-test method

Cup-plate method

Agar dilution streak

Antibacterial assay and broth dilution

Antibacterial assay and broth dilution

Agar-well diffusion

Agar dilution streak

Disc diffusion

Disc diffusion and broth dilution assay

Disc diffusion and broth dilution assay

Disc diffusion, broth dilution assay and radiometric BACTEC assay 0.25

Radio-respirometric measurement of ${ }^{14} \mathrm{CO}_{2}$ from the oxidation of palmitic acid

Radio-respirometric measurement of ${ }^{14} \mathrm{CO}_{2}$ from the oxidation of

palmitic acid

Radio-respirometric measurement of ${ }^{14} \mathrm{CO}_{2}$ from the oxidation of palmitic acid

Radio-respirometric measurement of ${ }^{14} \mathrm{CO}_{2}$ from the oxidation of

palmitic acid

Radio-respirometric measurement of ${ }^{14} \mathrm{CO}_{2}$ from the oxidation of

palmitic acid

Radio-respirometric measurement of ${ }^{14} \mathrm{CO}_{2}$ from the oxidation of

palmitic acid

Disc diffusion, Agar-well diffusion and agar dilution

Disc diffusion and agar dilution

Agar-well diffusion

Antibacterial assay and broth dilution
MIC

$(\mathrm{mg} / \mathrm{mL}) \quad$ Source

15

$>0.008$

(34)

(34)

(48)

$.0005 \quad$ (48)

$0.00075 \quad$ (48)

$0.000125 \quad$ (48)

(48)

NE (42)

NE (37)

$0.512 \quad$ (45)

$0.256 \quad$ (45)

$\mathrm{NE} \quad$ (37)

NE (30)

$0.125 \quad(49)$

(49)

(49)

(49)

(50)

(50)

(50)

$20 \quad$ (34)


Table 1. Continued

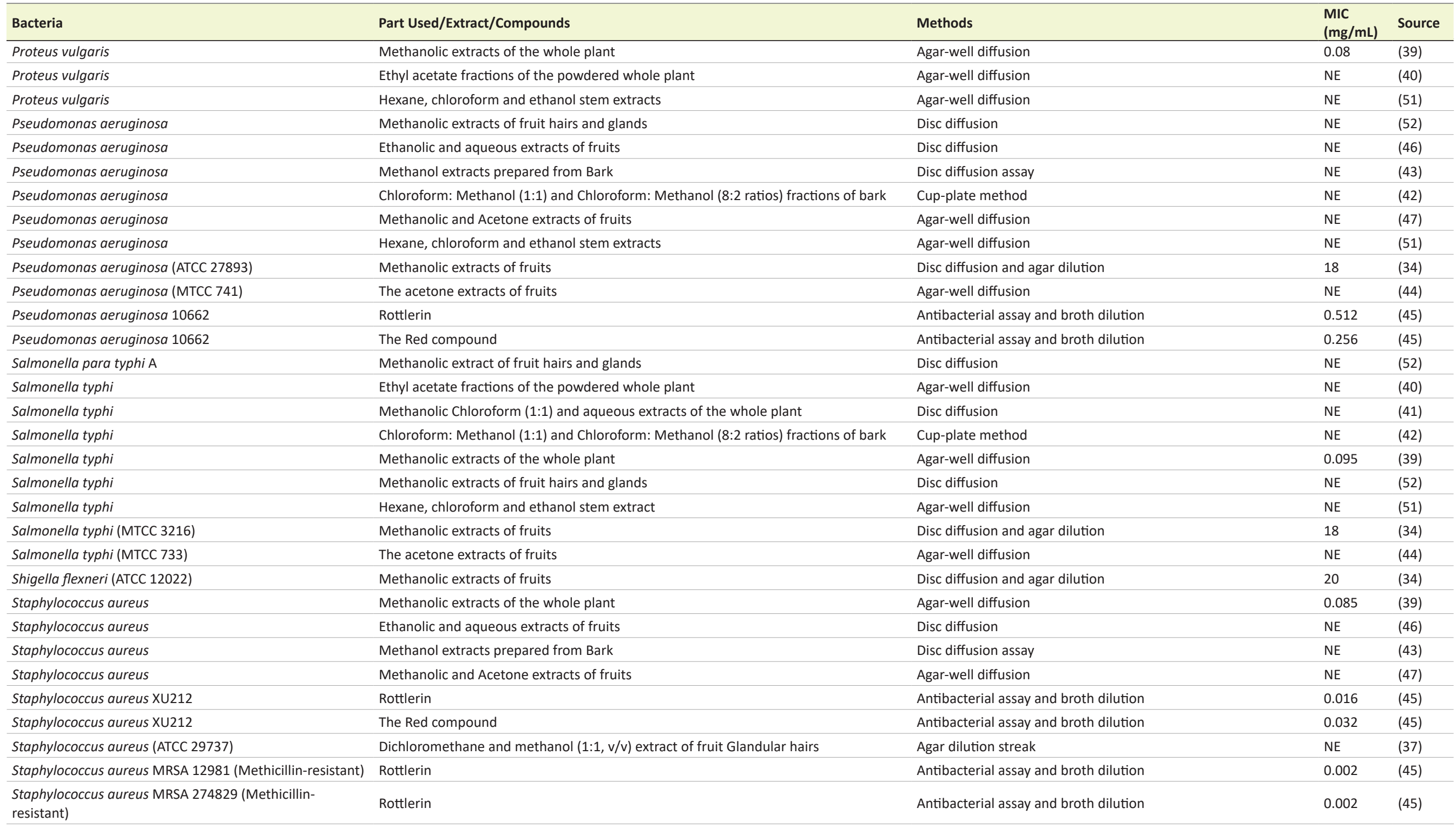


Table 1. Continued

\begin{tabular}{|c|c|c|c|c|}
\hline Bacteria & Part Used/Extract/Compounds & Methods & $\begin{array}{l}\text { MIC } \\
(\mathrm{mg} / \mathrm{mL})\end{array}$ & Source \\
\hline Staphylococcus aureus MRSA 346724 & Rottlerin & Antibacterial assay and broth dilution & 0.008 & (45) \\
\hline Staphylococcus aureus MRSA 774812 & Rottlerin & Antibacterial assay and broth dilution & 0.008 & (45) \\
\hline Staphylococcus aureus (Methicillin Sensitive) & Methanolic extract of Bark & Disc diffusion & NE & (30) \\
\hline Staphylococcus aureus (MTCC 96) & The acetone extracts of fruits & Agar-well diffusion & NE & (44) \\
\hline Staphylococcus aureus ATCC 25923 & The Red compound & Antibacterial assay and broth dilution & 0.032 & (45) \\
\hline Staphylococcus aureus ATCC 25923 & Rottlerin & Antibacterial assay and broth dilution & 0.004 & (45) \\
\hline Staphylococcus aureus RN4220 & The Red compound & Antibacterial assay and broth dilution & 0.032 & (45) \\
\hline Staphylococcus aureus RN4220 & Rottlerin & Antibacterial assay and broth dilution & 0.008 & (45) \\
\hline Staphylococcus aureus SA 1199B & The Red compound & Antibacterial assay and broth dilution & 0.032 & (45) \\
\hline Staphylococcus aureus SA 1199B & Rottlerin & Antibacterial assay and broth dilution & 0.002 & (45) \\
\hline Staphylococcus aureus (ATCC 25323) & Methanolic extract of fruits & Disc diffusion and agar dilution & 15 & (34) \\
\hline Staphylococcus aureus-15 (Epidemic Methicillin-Resistant) & Rottlerin & Antibacterial assay and broth dilution & 0.016 & (45) \\
\hline Staphylococcus aureus-15 (Epidemic Methicillin-Resistant) & The Red compound & Antibacterial assay and broth dilution & 0.032 & (45) \\
\hline Staphylococcus aureus-16 (Epidemic Methicillin-Resistant) & Rottlerin & Antibacterial assay and broth dilution & 0.032 & (45) \\
\hline Staphylococcus aureus-16 (Epidemic Methicillin-Resistant) & The Red compound & Antibacterial assay and broth dilution & 0.032 & (45) \\
\hline Staphylococcus epidermidis (ATCC 12228) & Dichloromethane and methanol $(1: 1, v / v)$ extract of fruit Glandular hairs & Agar dilution streak & NE & (37) \\
\hline Staphylococcus pneumoniae & Ethyl acetate fractions of the powdered whole plant & Agar-well diffusion & NE & (40) \\
\hline Streptococcus faecalis (MTCC 8043) & Dichloromethane and methanol $(1: 1, v / v)$ extract of fruit Glandular hairs & Agar dilution streak & NE & (37) \\
\hline Streptococcus pneumoniae & Hexane, chloroform and ethanol stem extract & Agar-well diffusion & NE & (51) \\
\hline Streptococcus pneumoniae (MTCC 655) & The acetone extracts of fruits & Agar-well diffusion & NE & (44) \\
\hline Vibrio parahaemolyticus (MTCC 451) & The acetone extracts of fruits & Agar-well diffusion & NE & (44) \\
\hline Vibrio species & Hexane, chloroform and ethanol stem extracts & Agar-well diffusion & NE & (51) \\
\hline Yersinia pestis & Methanolic and Acetone extracts of fruits & Agar-well diffusion & NE & (47) \\
\hline
\end{tabular}


reduced activity of NADPH oxidase (60). Furthermore, the anti-oxidant activity may also result from increased levels of enzymes such as superoxide dismutase (SOD) and catalase. This can be evidenced from the study, where $200 \mathrm{mg} / \mathrm{kg}$ of the methanolic extracts of leaves have exhibited their anti-oxidant effect by significantly increasing the levels of enzymatic (SOD and Catalase) and non-enzymatic biological anti-oxidants in the liver $(61,62)$.

There are little pieces of evidence of strong anti-oxidant activity of the plant and its extracts. Therefore, further studies should essentially include in vivo experiments rather than commonly used in vitro anti-oxidant assays. Although initial studies have indicated potential antioxidant activity of this plant, the specific compounds responsible for anti-oxidant activity and their mode of action are still unclear. Therefore, such studies need to be visited again and confirm if such properties really possessed by this tree.

\section{Anti-inflammatory activity}

As discussed earlier, some local people use leaves and seeds powder to get relief from rheumatism and associated joint pain. This use indicates the anti-inflammatory and immunoregulatory potential of the tree. When tested against different rat experimental models, methanol, ethanol and acetone extracts of fruits have shown encouraging results (63-65). For example, the ethanolic extract of fruit hairs significantly decreased the rat paw oedema induced by carrageenan and formalin (65) while ethyl acetate fraction of methanol extract reduced granuloma formation in carrageenan-induced paw oedema and cotton pellet induced granuloma method (64). A patent has been filed for antiallergic effects of phloroglucinol containing compositions prepared from fruit pericarps of this tree (66).

The acetone extract of the fruits has mallotophilippens (A, B, C, D and E) which are responsible for the inhibition of nitric oxide (NO) production induced by interferon- $\gamma$ (IFN- $\gamma$ ) and inhibition of histamine release from rat peritoneal mast cells $(65,67)$. Further, Mallotophilippen $\mathrm{C}$ and $\mathrm{D}$ achieve their actions by inhibiting inducible nitric oxide synthase (iNOS), cyclooxygenase-2 (COX2 ), interleukin-6 (IL-6), and interleukin-1 $\beta$ (IL-1 $\beta$ ) mRNA expression (67). In addition, a flavanone [7, 4'Dihydroxy-3", 3"-Dimethyl - (5, 6-Pyrano-2"- One) - 8(3"', 3"'-Dimethyl Allyl- flavanone] isolated from the plant remarkably lowered the serum cytokine (TNF- $\alpha$, IL- 6 and IL-1) levels and increased the activities of catalase and glutathione peroxidase in paw tissue (64).

Another compound isolated from the plant, rottlerin, also possessed the anti-allergic activity and blocks IgEmediated immediate release of $\beta$-hexosaminidase from mast cells in a concentration-dependent manner. It also inhibited IgE-induced phosphorylation of proteins, production of IP3 and raised in cytosolic $\mathrm{Ca}^{2+}$ level in mast cells (68). Similarly, a minimum dose of $10 \mathrm{mg} /$ $\mathrm{kg}$ of 11-O-galloylbergenin was significantly effective in reducing the carrageenan-induced paw oedema, but its mechanism of action is still not clear (69).

\section{Anti-cancer activity}

In the 1950s the fruit hairs extracted in hydrochloric acid showed tumour damaging effect in mice with Sarcoma 37 tumour (70). This was one of the initial reports of anti-cancerous activity of this plant. More recently, fruit hairs extracted in 95\% ethanol has shown cytotoxic activity against as many as 14 cancer cell lines. Further, the chloroform fraction of this extract was effective to inhibit the growth of several human cancer cell lines at a concentration of $100 \mu \mathrm{g} / \mathrm{mL}$ (71). On the other hand, hexane extract of the root possessed the significant anti-leukemic activity and induced apoptosis when tested against human promyelocytic leukaemia (HL60) cells (72). GC-MS analysis of this extract revealed the presence of polyphenolic compounds which were responsible for inhibited proliferation and induced apoptosis. Similarly, the compound 3a-hydroxy-D: Afriedooleanan-2-one isolated from the stem bark was identified to possess the anti-tumour activity (73) while another compound, 4'-hydroxyrottlerin (100 mg/mL) possessed antiproliferative activity and showed 54\% growth inhibition of Thp-1 leukaemia cell lines (74). Furthermore, a semisynthetic preparation of Mallotus B (isolated from the plant) has been reported to arrest cell cycle at the G1 phase and causing apoptosis among cancer cell lines (MIAPaCa-2 and HL-60 cells), thus exhibited anti-cancer activity (75).

\section{Rottlerin and Cancer}

Rottlerin regulates multiple signalling pathways to suppress tumour cell growth in different types of cancer cells, however, complete mechanisms are still unclear (reviewed by Maioli et al). The rottlerin induced apoptosis can either follow intrinsic or extrinsic pathways of cell death depending on cancer cell type. It is usually speculated that the antitumor activity of rottlerin is due to its ability to inhibit a class of protein kinases namely protein kinase $\mathrm{C}(\mathrm{PKC} \delta$ ) which have a protective role against apoptotic cell death. However, there is evidence available for $\mathrm{PKC} \delta$-independent cell death by rottlerin via mitochondrial uncoupling. The inhibition of PKC $\delta$ by rottlerin is achieved by activation of caspase-3, which cleaves PKC $\delta$ and prevents its translocation through the membrane (76). However, these findings need to be revisited as rottlerin seems no more a selective inhibitor of PKC $\delta$ (77).

In addition to apoptotic pathways, rottlerin also induces autophagy through different mechanisms. Rottlerin inhibits $\mathrm{PKC} \delta$ which regulates the transglutaminase 2 
(TG2) expression. This PKCס/TG2 inhibition downregulates targets like the phosphorylated mammalian target of rapamycin (mTOR), nuclear factor $\kappa \mathrm{B}(\mathrm{NF} \kappa \mathrm{B})$ and $\mathrm{Bcl}-2$ to promote autophagy. However, inhibition of NF $\kappa B$ might also be due to the activation of the AMPK pathway induced by rottlerin. Further, the anti-metastatic effects of rottlerin are again attributed to PKC $\delta$ inhibition, though it may reduce cell motility and cell adhesion independent of $\mathrm{PKC} \delta$ (76).

In MDA-MB-231 human breast cancer cells, rottlerin activates p38 Mitogen-activated protein kinase (MAPK) signalling pathway which enhances the expression of IL$1 \beta$-induced COX-2. Moreover, rottlerin also increased the expression of COX-2 induced by multiple reagents like tumour necrosis factor- $\alpha$ (TNF- $\alpha$ ), phorbol myristate acetate and lipopolysaccharide (78). At the molecular level, it is speculated that the induction of autophagy and apoptosis by rottlerin may be achieved by PI3K/Akt/ mTOR and AMPK signalling pathways because rottlerin is involved in the expression of many autophagy associated proteins especially Atg7 and Beclin-1 in prostate cancer stem cells (79). Another study showed that the inhibition of calmodulin-dependent protein kinase III prevented cellular growth and induced cytotoxicity in glioblastoma cell lines. Further, rottlerin down-regulates the expression of Cdc20 (cell-division-cycle protein 20) which is constitutively active in glioma cells (80). In pancreatic cancer cells, rottlerin significantly reduced the expression of Skp2 (S-phase kinase-associated protein 2), which was associated with human malignancies, indicating that Skp2 could be a potential target of rottlerin (81).

Anti-tuberculosis activity

Mycobacterium tuberculosis Zopf $1883(M t b)$ is naturally resistant to several drugs and antibiotics because of its unique cell wall structure which is neither gram-positive nor completely gram-negative (82). This is why it is hard to treat and traditional use of leaves and fruits for tuberculosis has opened a new window for researchers to test and validate its potential use. Primarily, ethanolic extracts of leaves and fruits have been tested and the results were encouraging. The ethyl acetate fraction of the ethanolic extract was effective at a MIC of $0.05 \mathrm{mg} / \mathrm{mL}$ as revealed by radiometric BACTEC assay (49). More recently, the ethanolic extracts of fruits are also reported to inhibit the growth of MDR strains of $M t b$ that are clinically isolated from the sputum of patients suffering from pulmonary tuberculosis. Interestingly, the resazurin microtiter plate assay showed that these MDR strains of $M t b(62.5 \mu \mathrm{g} / \mathrm{mL})$ were more susceptible as compared to $M t b \mathrm{H} 37 \mathrm{Rv}(250$ $\mu \mathrm{g} / \mathrm{mL})$. However, these extracts were not effective against human THP-1 macrophages at similar concentrations (83). Further, mallotophilippen F (8-cinnamoyl-5, 7-dihydroxy-2, 2-dimethyl-6-geranylchromene) and Red compound were identified as the active phytoconstituents for anti-tuberculosis activity against the $\mathrm{H} 37 \mathrm{Rv}$ strain of $M t b$ at a MIC of $16 \mu \mathrm{g} / \mathrm{mL}$ and $64 \mu \mathrm{g} / \mathrm{mL}$, respectively (50). Thus, there is a scope of developing drugs for tuberculosis based on this medicinally important tree.

\section{Hepato-protective activity}

As mentioned earlier, seed powder is traditionally used to treat jaundice by some indigenous communities. Several drugs including paracetamol may cause damage to liver-cells and interfere with the normal functioning of the hepatic system of the body. Often hepato-toxicity is associated with increased levels of malondialdehyde, bilirubin and decreased activity of enzymes such as serum glutamic oxaloacetic transaminase (SGOT), serum glutamic pyruvic transaminase (SGPT) and serum alkaline phosphatase (SALP). Methanolic extracts of leaves were tested for hepato-protective activity against $\mathrm{CCl}_{4}$-induced hepatotoxicity and oxidative stress. The extracts significantly reversed the $\mathrm{CCl}_{4}$-induced changes in biochemical, functional, histological and anti-oxidant parameters of hepatotoxicity. A dose of $200 \mathrm{mg} / \mathrm{kg}$ of the extracts significantly reduced the sleep time, increased the levels of enzymes SGOT, SGPT, SALP in addition to bilirubin and protein content $(61,62)$. Furthermore, there was a significant increase in the levels of enzymatic (SOD and catalase) and non-enzymatic biological anti-oxidants in liver indicating that anti-oxidant property may also be a responsible factor for hepato-protective activity $(61,62)$. However, no specific chemical compound was identified and characterised for hepato-protective activity so far from this particular plant.

Wound healing activity

As discussed in the previous section, many local communities still employ traditional formulations prepared from fruits, bark and the whole plant for treating wounds. There is evidence available for wound healing activity of bark and fruits extracts of this plant. For instance, the ethanolic extract of bark enhanced the mobilization of mesenchymal stem cells towards the wounded areas possibly due to the effects of Cinnamtannin B-1 in a diabetic mouse model (84). Similarly, the bark extracted in aqueous ethanol had the ability to attract mesenchymal stem cells thus effective against tissue injuries and this potential of the tree was granted a patent also (85). Another study showed that the fruit glandular hair extracts stimulated collagen synthesis, anti-oxidant effects through peroxidase enzymes and inflammatory cytokines in rats (86). Thus, it seems that it has the potential to effectively heal wounds, though specific potent compounds that have not been isolated and developed, yet.

\section{Anti-parasitic activity}

The traditional use of different components of this tree to treat various skin ailments caused by common parasites 
indicates its anti-parasitic activity. The broad-spectrum anti-parasitic activity of several phytoconstituents isolated from different parts of the plant supports these traditional uses. For example, Kamalachalcone E and 1-(5, 7-Dihydroxy-2, 2, 6-trimethyl-2H-1-benzopyran-8-yl)-3phenyl-2-propen-1-one, both exhibited good antifungal activity against Cryptococcus neoformans PRL518, C. neoformans ATCC 32045 and Aspergillus fumigatus NCIM 902 (74). Two chalcone derivatives, Mallotoate A and Mallotoate B were isolated from ethyl acetate fraction of methanolic extracts using chromatographic techniques. Both compounds (mallotoate $\mathrm{A}$ and mallotoate $\mathrm{B}$ ) have shown significant fungicidal activities against Cladosporium cladosporioides in TLC bio-autography method (87). Similarly, Bergenin and 11-O-galloylbergenin isolated from aqueous fractions of ethanolic extracts of stem wood exhibited good anti-plasmodial activity against Chloroquine sensitive strain of Plasmodium falciparum. However, the in silico molecular docking analyses using P. falciparum proteins PfLDH and Pfg27 indicated that 11-O-galloylbergenin had high docking score and binding affinity to both protein receptors as compared to Bergenin (55). Moreover, rottlerin potently inhibited the growth of Toxoplasma gondii (88), Chlamydia (89), several resistant bacterial strains (45), and some clinical $H$. pylori isolates (48). Furthermore, rottlerin and the red compound (100 $\mathrm{mg} / \mathrm{mL}$ ) significantly inhibited the conjugal transfer of plasmids pKM101, TP114 and pUB307 amongst Escherichia coli without binding directly to plasmid DNA (45). Thus, there is good evidence of anti-parasitic activity of phytochemicals isolated from this tree. These compounds can offer drug discovery and development opportunities for the upcoming future.

\section{Analgesic activity}

Bark, fruit and leaves are used to treat pain by various ethnic groups as described earlier and only a few studies have tested this potential of the tree. For example, ethanolic extract of fruit hairs was reported to significantly increase both pre- and post-drug pain reaction time in Tail flick method and hot plate test. Moreover, the extract has shown significant antinociceptive activity in terms of the significant decrease in acetic acid-induced writhes (63). The probable active constituent for analgesic activity can be 11-O-galloylbergenin, which has been shown to be effective against the formalin test in rats at the doses of 20 and $40 \mathrm{mg} / \mathrm{kg}$ (69). These studies have provided some shreds of evidence of analgesic activity; however, modern in vitro and in vivo assays may be implicated to produce more authentic evidence in order to develop it as a novel drug.

\section{Anti-urolithiatic activity}

Kamala fruits are used for the treatment of kidney stones in Indian folklore (90). A traditional Ayurvedic preparation is known as the Vidangadi churna also contains Kamala as one of its major constituents. This formulation has been claimed to possess anti-urolithiatic activity (91). Although well-replicated experiments using in vivo methods are still lacking. However, a probable mechanism of action may involve disruption of oxalate/calcium oxalate-induced signalling pathways of oxidative stress. This can be achieved by rottlerin, an active constituent of the plant, which has the ability to quench free radicals. A study conducted on male Wistar rats has shown that rottlerin can potentially prevent stone formation in kidneys probably involving the above mechanism (60).

Anti-viral activity

There is only a single study available in literature where the anti-viral activity of this plant has been tested. The methanolic extract of the bark has considerably reduced the infectivity of the Sindbis virus and human poliovirus- 1 at concentrations of $200 \mu \mathrm{g} / \mathrm{mL}$ and $50 \mu \mathrm{g} /$ $\mathrm{mL}$, respectively. However, the same extract inactivated the Herpes simplex virus- 1 at $100 \mu \mathrm{g} / \mathrm{mL}$ in the dark whereas it was only partially active at concentration of $50 \mu \mathrm{g} / \mathrm{mL}$ in the presence of UV-A radiation and at a concentration of $25 \mu \mathrm{g} / \mathrm{mL}$ in dark and visible light (92). Initial results of this study indicate that the tree may have the potential to cure viral diseases which demand further investigations for exploration of this property.

\section{Toxicological reports}

Although Kamala has not been reported to be toxic for human beings so far, it has been shown to reduce fertility in several animals like goats, pigs and rats. However, the first toxicity report was published in 1960, where it was shown that ethereal extracts of the plant interfere with pregnancy and implantation in rats and guinea pigs (93). Subsequently, rottlerin was identified as the active compound responsible for the reduced pregnancy in these animals (94). Later, it was speculated that the altered oestrous cycle (including follicular development, ovulation and corpora lutea formation) and pregnancy in rats caused by the ethereal extracts of seeds were primarily due to the reduction in serum level hormones like FSH, LH and estradiol (95). On the other hand, the Kamala powder, its water or methanol extracts and even the glycosides and Nilzan ${ }^{\circledR}$ produced transitory diarrhoea and restlessness, which vanished in a few hours in naturally cestode-infected Beetal goats (96). Traditional fishermen of Chitwan district of Nepal, use the bark of the tree to kill fishes. This toxicity was validated on grass carp (Ctenopharyngodon idella) fingerlings using water as control where $0.23 \%(\mathrm{w} / \mathrm{v})$ extract killed $50 \%$ fishes in 2 hours (97). However, the active compound and mechanism of action are yet to be investigated. In case of human beings, only the pollen antigens of the tree induce skin reactivity and skin sensitivity in patients residing in the foothills of the Himalayas (98) and from other parts of India (99). 


\section{Phytochemistry}

The earlier section has shown that almost all parts of the tree are gifted with more than one kind of biological activity, if not many. However, crude extracts usually contain diverse chemical constituents and not all the active components are extracted in a single solvent. Therefore, it is imperative to identify the specific chemical constituent responsible for a particular pharmacological activity. In the present section, various phytoconstituents that can be extracted from different parts of the tree, are discussed in brief and in the last subsection, artificial synthesis of major chemical constituents is also highlighted.

\section{Phytoconstituents}

The phytochemistry and pharmacology of Vietnamese Mallotus have been already comprehensively reviewed (9) and these are summarised in Table 2. Kamala oil obtained from the seeds contains unsaturated fatty acids $\alpha$ - and $\beta$-kamlolenic acid (18-hydroxy- $\Delta 9$ cis, 11 trans, 13 transoctadecatrienoic acid) with small amounts of linoleic, oleic and eicosenoic acid. A patent has also been granted for the isolation of $\alpha$-kamlolenic acid from the fatty acids of the seed oil of Kamala using alcoholic potash and its transformation to $\beta$-kamlolenic acid has been achieved by dissolving in a mixture of petrol ether and iodine crystals (100). The saturated fatty acids consist mostly of myristic acid, palmitic acid and stearic acid $(101,102)$. The fermented seeds also have cardenolides, corotoxigenin, coroglaucigenin and L-rhamnoside derivatives (103) (Figure 2).

The heartwood and stem bark yield several pentacyclic triterpenoids (Figure 2). The lupane type triterpenoids include betulin, betulin-3-acetate, lupeol and lupeol acetate $(73,104)$. Friedelane type triterpenoids yielded from chloroform and petrol extract of stem bark are friedelin, 2 $\beta$-hydroxy-D: A-friedooleanan-3-one; 3-hydroxy-D: A-friedoolean- 3-en-2-one and; 3a-hydroxy-D: Afriedooleanan-2-one $(73,105)$. Other triterpenoids yielded from the wood and bark include acetylaleuritolic acid (Figure 2), $\alpha$-amyrine (104), 3 $\beta$-acetoxy-22 $\beta$ hydroxyolean-18-ene and kamaladiol (105). Moreover, steroids like $\beta$-sitosterol, daucosterol (104), and isocoumarins bergenin and 11-O-galloylbergenin were also reported from the wood and bark of the tree $(55,104,106)$.

As many as 15 different types of tannins and related compounds were isolated from leaves of the tree (106) (Figure 3). Fruits are rich in phytochemicals including phenolic compounds, flavonoids, phloroglucinol derivatives, chalcone derivatives and several others. So far, five chalcone derivatives known as kamalachalcones (A, B, C, D and E) have been reported from fruit powder $(74,107,108)$ (Figure 4). Another characteristic class of compounds called as Mallotophilippens (A, B, C, D, E and $\mathrm{F}$ ) were isolated and characterised from the fruits of the tree $(50,65,67,109)$ (Figure 5). Recently, bilariciresinol was isolated for the first time from the leaves, along with platanoside, isovitexin, dihydromyricetin, bergenin, 4-O-galloylbergenin and pachysandiol A (110).

The major constituents of Kamala are phloroglucinol derivatives rottlerin, 4'-hydroxyrottlerin, isorottlerin, 4'-hydroxy-isorottlerin, isoallorottlerin, Red and Yellow compounds (also known as Kamalins) which are present chiefly in fruit powder known as Kamala (48, 50,74,108,111,112) (Figure 6). Moreover, Flavanones like 5, 7-dihydroxy-8-methyl-6-prenylflavanone; 6, 6-dimethylpyrano (2", 3": 7, 6)-5-hydroxy-8methyl flavanone (108), 3'-prenylrubranine (48) (Figure 7) and 8-cinnamoyl-2, 2-dimethyl-7-hydroxy-5methoxychromene were also isolated from the flowers and fruits of the tree (50). Thus, most of the phytochemicals have been isolated and characterised from the fruits (21\%), followed by leaves (13\%), bark (12\%), seeds (11\%), wood $(6 \%)$ and flowers (3\%).

\section{Synthesis of phytoconstituents in laboratory}

Several attempts have been made for isolation and synthesis of the biologically active chemical compounds that are naturally present in the tree (109,113-115). The first total synthesis of mallotophilippen C was achieved from phloroacetophenone (109) whereas mallotophilippen $\mathrm{C}$ and $\mathrm{E}$ might also be synthesized from 2, 4, 6-trihydroxyacetophenone (113). Synthetic approaches have also been described for isolation and synthesis of mallotophilippens D and F, Red compound, and their unnatural derivatives from organic extracts (114).

A semisynthetic preparation of mallotus $B$, a prenylated dimeric phloroglucinol compound isolated from the tree has also been achieved via base mediated intramolecular rearrangement of rottlerin (75). Recently, the total synthesis of rottlerin was achieved in the longest 8 linear steps with $20 \%$ overall yield (115). However, more efficient isolation and synthesis are still required for industriallevel production of these medicinally active compounds.

\section{Conclusion}

The pharmacological activities and isolation of active phytochemicals scientifically validate and support the traditional uses of this particular plant. So far, more than 50 phytochemicals have been identified and tested for about 12 types of in vitro pharmacological activities from the crude extracts of the plants. Rottlerin and mallotophilippens have emerged as the potential active compounds that can be transformed into effective drugs for future prospects. The pharmacological activities of rottlerin and its mechanism of action are still under investigation. Laboratory synthesis of these active chemicals have been attempted; however, the yield is very low, therefore further efforts are still needed.

Despite some recent advances about the pharmacology and phytochemistry of this tree, several knowledge 
Table 2. Various Phytoconstituents reported from Mallotus philippensis (Lam.) Müll. Arg. tree

\begin{tabular}{|c|c|c|c|}
\hline Category & Source parts & Phytoconstituent (PubChem CID) & Reference \\
\hline \multicolumn{4}{|l|}{ Cardenolides } \\
\hline Cardiac glycosides & Seeds & Coroglaucigenin (12302399); Corotoxigenin (12302397); Coroglaucigenin L-rhamnoside; Corotoxigenin L-rhamnoside; & (103) \\
\hline \multicolumn{4}{|l|}{ Triterpenoids } \\
\hline Lupane-type & Stem bark & Betulin (72326); & (73) \\
\hline Lupane-type & Heartwood & Betulin-3-acetate (479957); & (104) \\
\hline Lupane-type & Heartwood & Lupeol (259846); & $(73,104)$ \\
\hline Friedelane-type & Stem bark & Friedelin (91472); & $(73,105)$ \\
\hline Friedelane-type & Stem bark & $2 \beta$-hydroxy-D: A-friedooleanan-3-one; 3-hydroxy-D: A-friedoolean-3-en-2-one; 3 $\alpha$-hydroxy-D: A-friedooleanan-2-one; & (73) \\
\hline Pentacyclic triterpenoids & Bark & Acetylaleuritolic acid (161616); & (104) \\
\hline Pentacyclic triterpenoids & Stem bark & Kamaladiol; $2 \beta$-acetoxy-22ß-hydroxy olean-18-ene or Kamaladiol-3-acetate; & (105) \\
\hline Ursane type & Bark & $\alpha$-amyrine (73170) & $(104)$ \\
\hline \multicolumn{4}{|l|}{ Flavonoids } \\
\hline Chalcone derivative & Fruits & Kamalachalcone C (101721039); Kamalachalcone D (101721040); & $(108)$ \\
\hline Chalcone derivative & Fruits & Kamalachalcone E & (74) \\
\hline Phloroglucinol derivatives (Kamalins) & Fruits & Rottlerin (5281847) & $(50,74,108,112)$ \\
\hline Phloroglucinol derivatives & Fruits & 4'-hydroxy-isorottlerin (5318333) & $(74,108)$ \\
\hline Phloroglucinol derivatives & Fruits & Isoallorottlerin & $(48,50,108,112)$ \\
\hline Phloroglucinol derivatives & Fruits & Isorottlerin (5318656) & $(48,50,108)$ \\
\hline Phloroglucinol derivatives & Fruits & Red compound (85441307); Yellow compound; Methylene-bis-methyl phloro acetophenone; & (112) \\
\hline Phloroglucinol derivatives & Fruits & Mallotophilippen A (10185281); Mallotophilippen B (10205431); & (65) \\
\hline Chalcone derivatives & Fruits & Mallotophilippen C (10050581); Mallotophilippen D (9983046); Mallotophilippen E (10458296) & $(67,109)$ \\
\hline Chromene derivatives & Flowers & Mallotophilippen F & (50) \\
\hline
\end{tabular}


Table 2. Continued

\begin{tabular}{|c|c|c|c|}
\hline Category & Source parts & Phytoconstituent (PubChem CID) & Reference \\
\hline Chromene derivatives & Flowers & 8-cinnamoyl-2,2-dimethyl-7-hydroxy-5-methoxychromene; 8-cinnamoyl-5,7-dihydroxy-2,2,6-trimethylchromene (Red Compound) (85441307) & $(45,50)$ \\
\hline Flavanones & Fruit powder Kamala & 5, 7-dihydroxy-8-methyl-6-prenylflavanone (42607875); & $(48,108)$ \\
\hline Flavanones & Fruit powder Kamala & 6, 6-dimethylpyrano (2", 3": 7, 6)-5-hydroxy-8-methylflavanone; & (108) \\
\hline Flavonoid & Fruits & Red Compound (85441307); & $(48,74)$ \\
\hline Flavonoid & Fruits & 3'-prenylrubranine (42607682); & (48) \\
\hline \multicolumn{4}{|l|}{ Phenolic Compounds } \\
\hline Isocoumarins & Heartwood, bark and leaves & Bergenin (66065); & $(55,104,106)$ \\
\hline Isocoumarins & Stem wood & 11-O-Galloylbergenin (56680102); & (55) \\
\hline Tannins & Leaves & $\begin{array}{l}\text { 6-O-Galloylbergenin; Norbergenin (73192); 3-O-galloylnorbergenin; Tergallic acid dilactone; } \\
\text { Corilagin (73568); Geraniin (3001497); Furosin (10416810); Mallotinic acid (10056140); Mallotusinic acid (16131237); Flavogallonic acid } \\
\text { (71308199); Brevifolin carboxylic acid (9838995); 2,3-(S)-hexahydroxy diphenoyl-D-glucose; Repandusinic acid A monopotassium salt; }\end{array}$ & (106) \\
\hline \multirow[t]{2}{*}{ Fatty acids } & Seeds & $\alpha$-Kamlolenic acid (5282949); $\beta$-Kamlolenic acid (5282950); & $(101,102)$ \\
\hline & Seeds & Linolenic acid (5280934); Oleic acid (445639); Eicosenoic acid; Palmitic acid (985); Stearic acid (5281); & (101) \\
\hline \multirow[t]{2}{*}{ Steroids } & Heartwood and Bark & B-Sitosterol (222284); & (104) \\
\hline & Bark & Daucosterol (5742590); & (104) \\
\hline
\end{tabular}




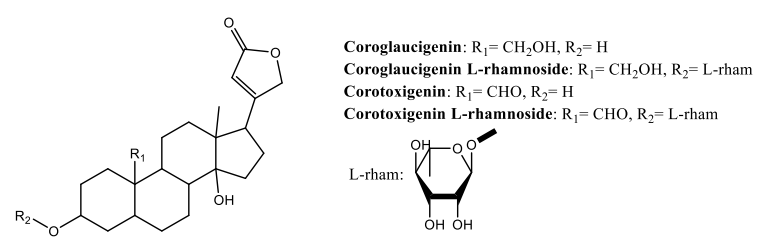

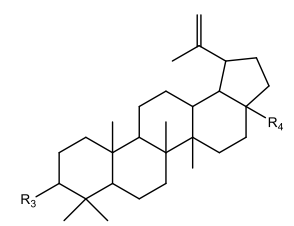

Betulin: $\mathrm{R}_{3}=\mathrm{OH}, \mathrm{R}_{4}=\mathrm{CH}_{2} \mathrm{OH}$

Betulin-3-actate: $\mathrm{R}_{3}=\mathrm{OCOCH}_{3}, \mathrm{R}_{4}=\mathrm{CH}_{2} \mathrm{OH}$ upeol: $\mathrm{R}_{3}=\mathrm{OH}, \mathrm{R}_{4}=\mathrm{CH}_{3}$

Lupeol-3-acetate: $\mathrm{R}_{3}=\mathrm{OCOCH}_{3}, \mathrm{R}_{4}=\mathrm{CH}_{3}$<smiles>CC1C(=O)[C@H](C)CC2C3CCC4(C)C(C)CCC(C)(C)C4CCC3(C)C1CCC2(C)C</smiles><smiles>CC1C(=O)C(O)CC2(C)C1(C)CCC1C3(C)CCC4(C)CCC(C)(C)CC4C3CCC12C</smiles>

23-hydroxy-D:A-friedooleanan-3-one: $\mathrm{R}_{5}=\mathrm{OH}$ Friedelin: $\mathrm{R}_{5}=\mathrm{H}_{2}$

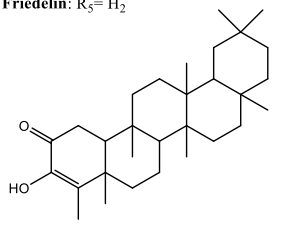

3-hydroxy-D:A-friedoolean-3-en-2-on

Figure 2. Chemical structures of cardenolides and triterpenoids isolated from this tree.<smiles>[R6]C1OC2c3c(cc(O)c(O)c3O)C(=O)OC2C(O)C1O</smiles>

Bergenin: $\mathrm{R}_{1}=\mathrm{H}, \mathrm{R}_{2}=\mathrm{H}, \mathrm{R}_{3}=\mathrm{CH}_{3}$

6-O-galloylbergenin: $\mathrm{R}_{1}=\mathrm{H}, \mathrm{R}_{2}=\mathrm{G}, \mathrm{R}_{3}=\mathrm{CH}_{3}$

orgenin: $\mathrm{R}_{1}=\mathrm{H}, \mathrm{R}_{2}=\mathrm{H}, \mathrm{R}_{3}=\mathrm{H}$

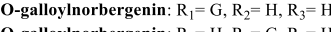

6-O-galloylnorbergenin: $R_{1}=H, R_{2}=G, R_{3}=H$

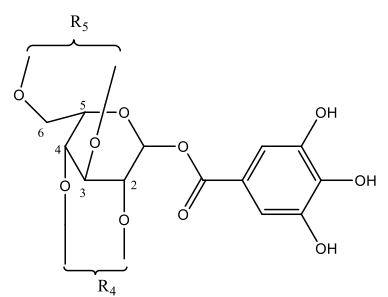

Corilagin: $R_{4}=H, H ; R_{5}=H H D$ Geraniin: $R_{4}=D H H D P, R_{5}=H H D$ Furosin: $\mathrm{R}_{4}=\mathrm{DHHDP}, \mathrm{R}_{5}=\mathrm{H}, \mathrm{H}$ Mallotinic acid: $\mathrm{R}_{4}=\mathrm{H}, \mathrm{H} ; \mathrm{R}_{5}=\mathrm{Val}$ Mallotusinic acid: $\mathrm{R}_{4}=$ DHHDP, $\mathrm{R}_{5}=\mathrm{V}$
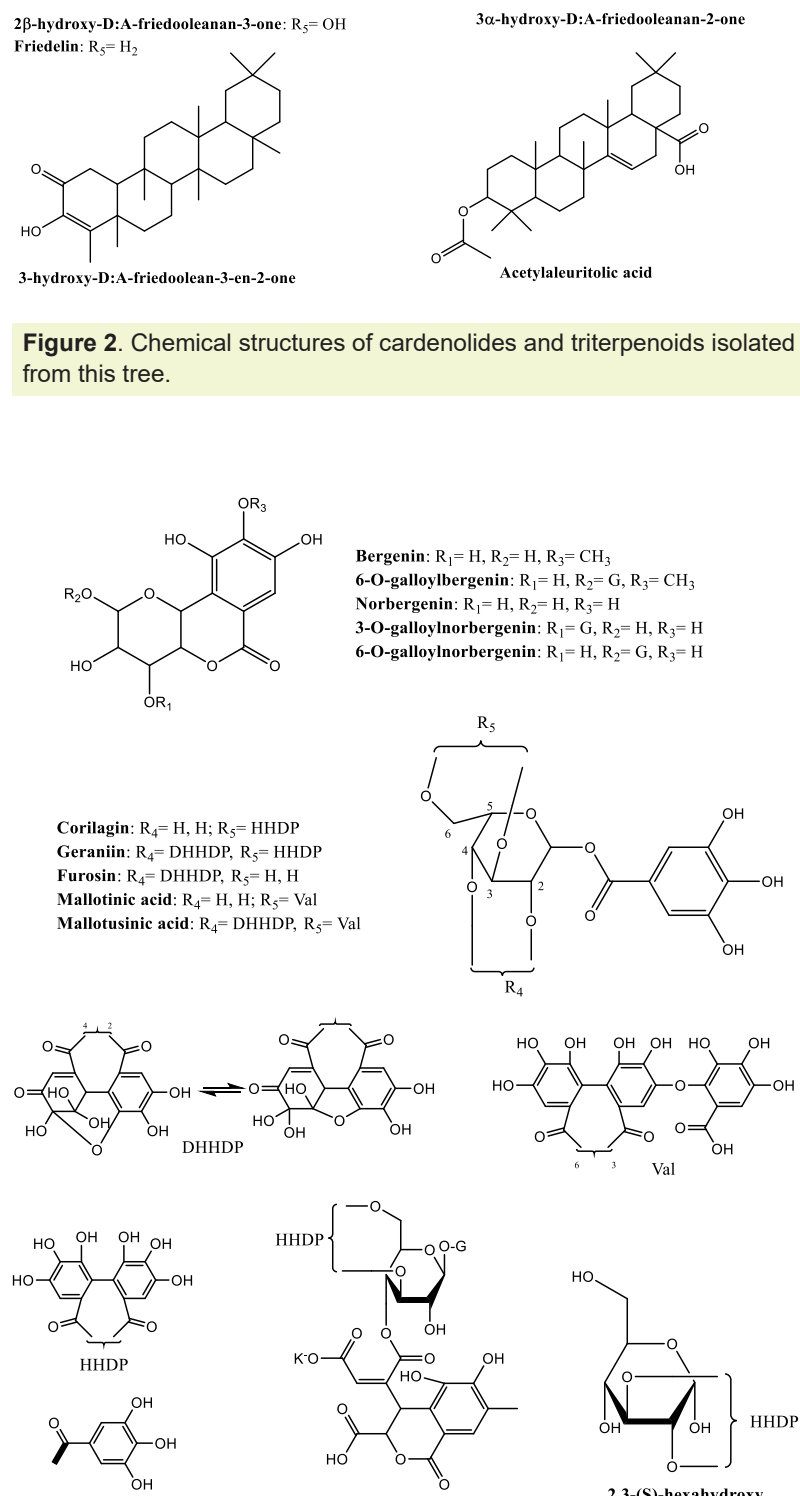

Galloyl: G Repandusinic acid A

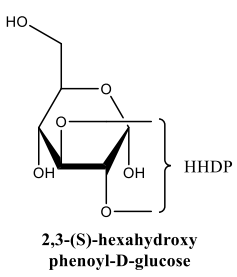

Figure 3. Chemical structures of tannins isolated from this tree.

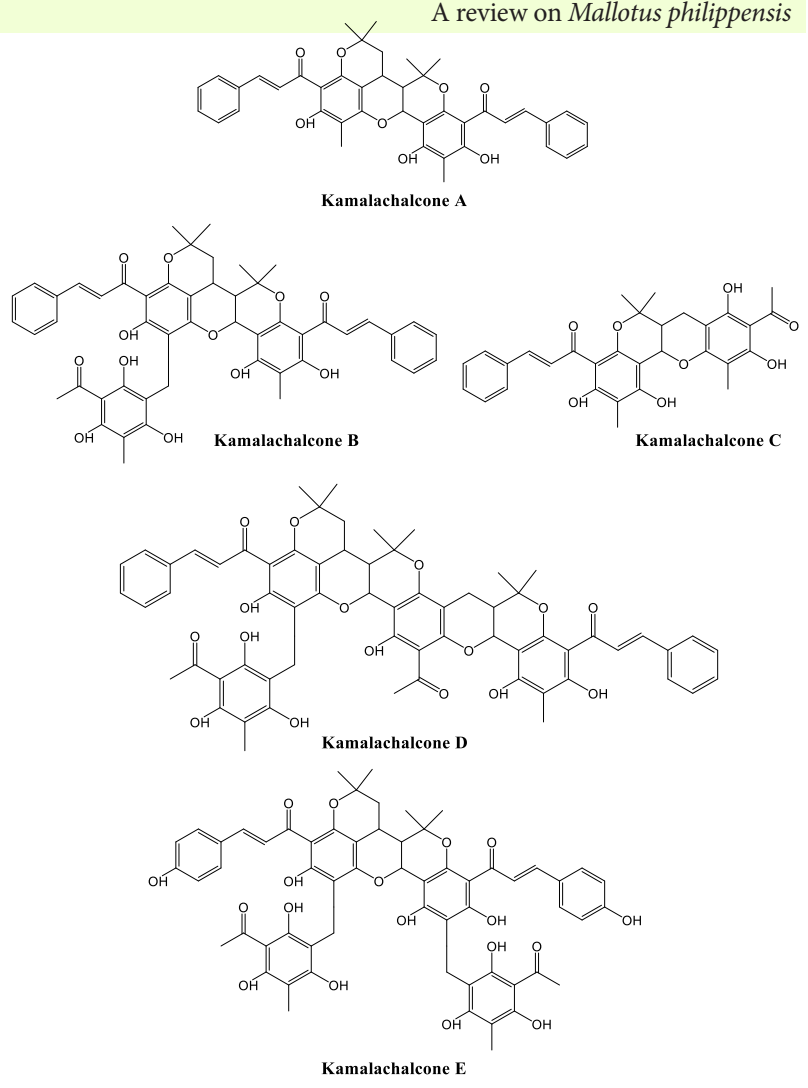

Figure 4. Chemical structures of kamalachalcones isolated from this tree.

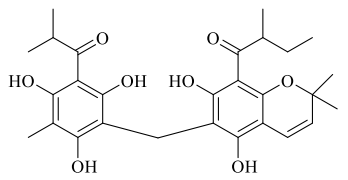

Mallotophilippen A

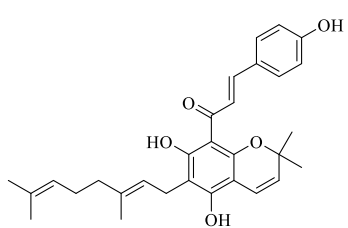

Mallotophilippen C

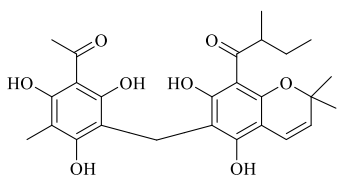

Mallotophilippen B

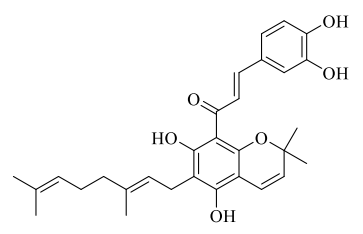

Mallotophilippen D

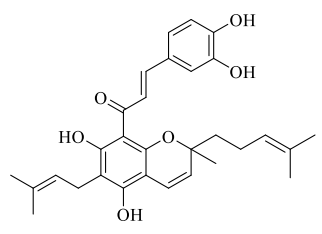

Mallotophilippen E

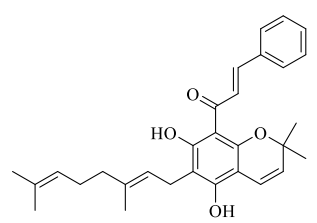

Mallotophilippen F

Figure 5. Chemical structures of Mallotophilippens isolated from this tree. 


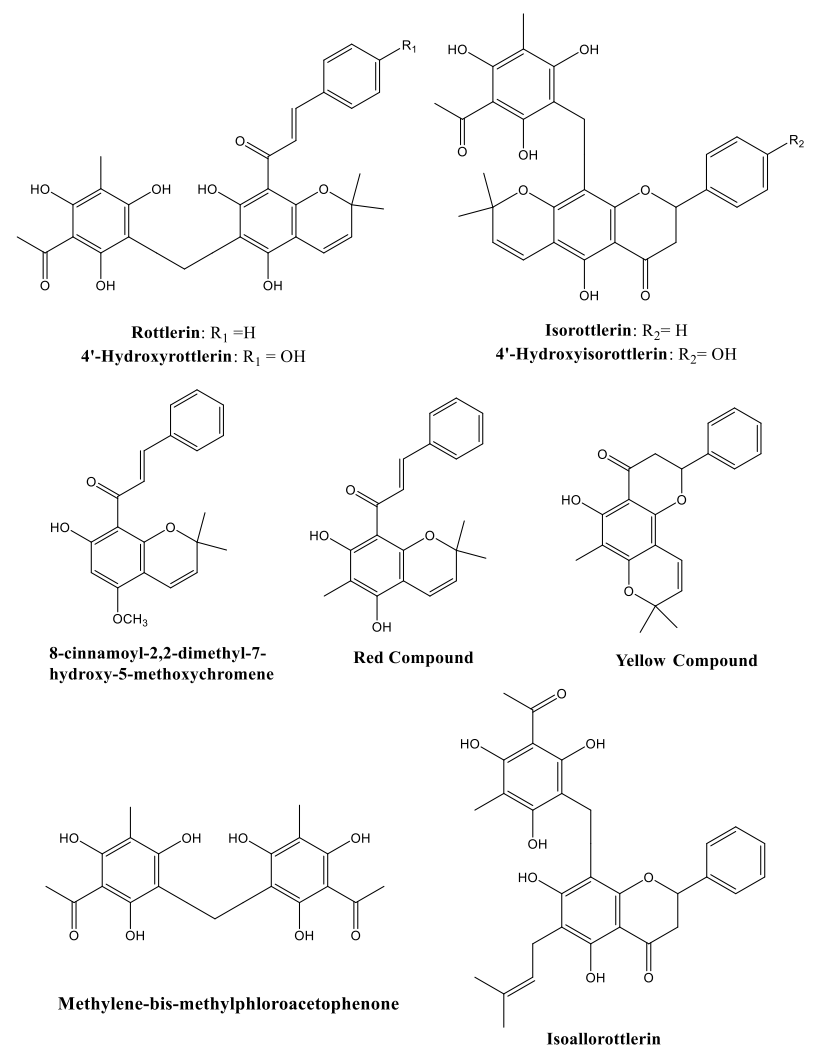

Figure 6. Chemical structures of major phloroglucinol derivatives (kamalins) isolated from this tree.

gaps and shortfalls are identified. Only a few studies tested pharmacological activities in vivo and most of the reported data is based on in vitro studies. Further, the majority of studies have used crude extracts and there is need to identify the active chemicals, their mode of action and mechanisms in order to develop novel drugs. Several pharmacological studies still used primitive crude methods to assess the biological activities (disc diffusion, agar-well diffusion assays for antibacterial activity and $\mathrm{DPPH}$, reducing power assay, total anti-oxidant capacity assays for anti-oxidant activities). Although these methods can be useful for initial screening of extracts, they can be sometimes misleading and non-specific. Furthermore, many studies reporting antibacterial potential have not evaluated MIC for the extract, therefore, their efficacy is not clear. Thus, more sophisticated and advanced techniques may be included for validation and reconfirmation of these biological activities in vitro followed by proper trial using human-disease based models. In addition, data on toxicological activities of the tree is deficient and often neglected, and long-term safety concerns are not clear.

\section{Acknowledgement}

Authors are grateful to the Chairperson, Department of Botany, Panjab University, Chandigarh, for providing all necessary facilities required for work. We are also deeply
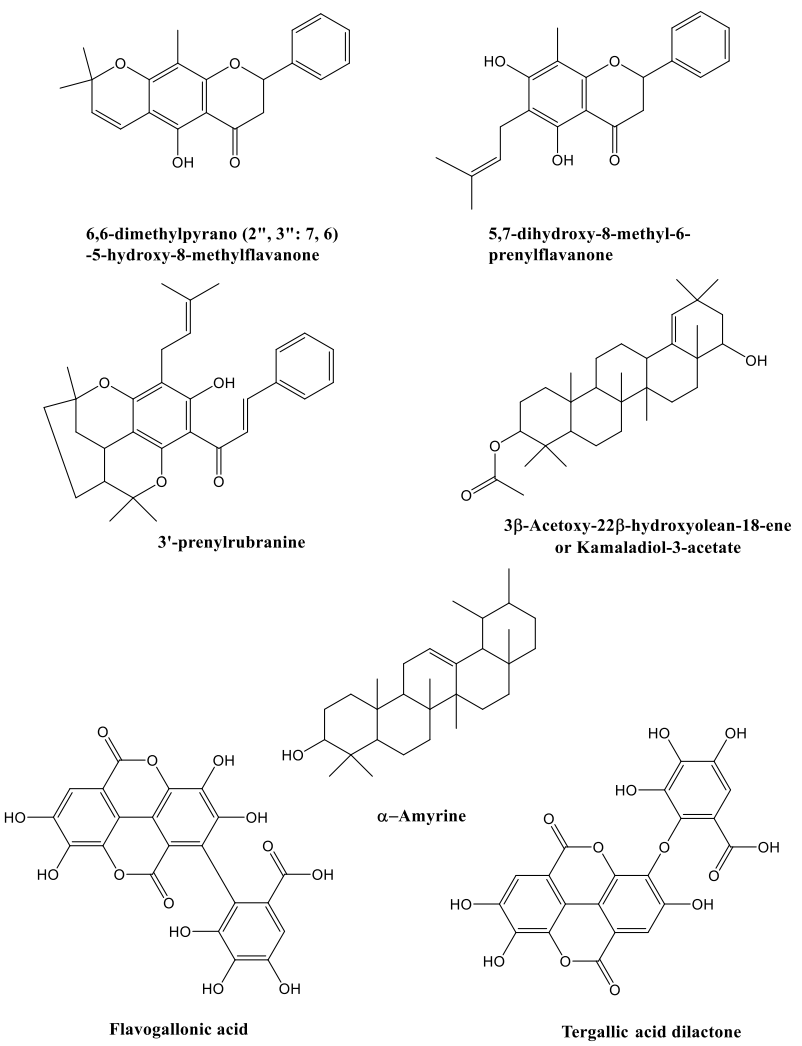

Figure 7. Chemical structures of some flavonoids, triterpenoids and tannins isolated from this tree.

grateful to Prof. Michael Heinrich, for his critical, valuable and constructive comments to earlier version of this manuscript.

\section{Authors' contribution}

All authors have equally contributed to the literature survey and collected the data from the various published articles to be included in the manuscript. AK chiefly drafted the final version of the manuscript and prepared all the figures and chemical structures. MP prepared all the tables and arranged references for the manuscript. PK contributed the photographs of the tree. RK, NKS and ANS conceptualized and drafted the initial version of the manuscript. PK, RCB, RK and NKS critically read and suggested important revisions for the manuscript. ANS supervised and monitored the progress of the manuscript. All authors have read, given feedback and approved the final manuscript for publication.

\section{Conflict of interests}

Authors declare no conflict of interests.

\section{Ethical considerations}

Ethical issues regarding authorship, data acquisition, review and analysis have been carefully observed by authors. 


\section{Funding/Support}

This work was supported by the University Grants Commission, Government of India, New Delhi in the form of Junior Research Fellowship [UGC Ref. No.: 507-(OBC) (CSIR-UGC NET DEC. 2016)]. The corresponding author acknowledges to Department of Science and Technology, Government of India for support in the form of PURSE Grant.

\section{References}

1. Newman DJ, Cragg GM, Snader KM. Natural products as sources of new drugs over the period 1981-2002. J Nat Prod. 2003;66(7):1022-37. doi: 10.1021/np030096l.

2. Khare CP. Indian Medicinal Plants: An Illustrated Dictionary. Berlin/Heidelberg: Springer-Verlag; 2007:302.

3. Usmanghani K, Saeed A, Alam M. Indusyunic Medicine: Traditional Medicine of Herbal, Animal, and Mineral Origin in Pakistan. Karachi: University of Karachi; 1997. p. 591.

4. Nadkarni AK. Dr. K. M. Nadkarni's Indian Materia Medica. Bombay and Panvel: Popular Book Depot, Bombay and Dhootapapeshwar Prakashan Ltd, Panvel; 1976:974.

5. Ahmad SS, Mahmood F, Dogar Z, Iqbal Khan Z, Ahmad K, Sher M, et al. Prioritization of medicinal plants of Margala Hills National Park, Islamabad on the basis of available information. Pak J Bot. 2009;41(5):2105-14.

6. Gupta AG. Ethnobotanical Studies of Mount Abu Region in Sirohi District Rajasthan [thesis]. Jaipur: University of Rajasthan; 2015.

7. Kirtikar KR, Basu BD. Indian Medicinal Plants. VolumeIII. Allahabad, India: Lalit Mohan Basu, Allahabad; 1935. p. 2268.

8. Haque Z, Ahmed T, Mand D, Asma K, Rumman, Alam A. Medicinal effect of Kameela and Amraze Jildiya (skin diseases) described in Unani system of medicine and current research - an overview. Int J Pharmacogn. 2015;2(10):494-6.

9. Rivière $C$, Nguyen Thi Hong V, Tran Hong Q, Chataigné G, Nguyen Hoai N, Dejaegher B, et al. Mallotus species from Vietnamese mountainous areas: phytochemistry and pharmacological activities. Phytochem Rev. 2010;9(2):21753. doi: 10.1007/s11101-009-9152-6.

10. Gangwar M, Goel RK, Nath G. Mallotus philippinensis Muell. Arg (Euphorbiaceae): ethnopharmacology and phytochemistry review. Biomed Res Int. 2014;2014:213973. doi: 10.1155/2014/213973.

11. Sharma J, Varma R. A review on endangered plant of Mallotus philippensis (Lam.) M. Arg. Pharmacologyonline. 2011;3:1256-65.

12. Dhaker JK, Sharma K. Ethnopharmacology review on Endangered medicinal plants. Int J Pharm Biomed Res. 2014;1(1):1-6.

13. Tripathi IP, Chaudhary P, Pandey P. Mallotus philippensis: a miracle stick. World J Pharm Res. 2017;6(7):678-87. doi: 10.20959/wjpr20177-8816.

14. R Development Core Team. R: A Language and Environment for Statistical Computing. Vienna, Austria: R Foundation for Statistical Computing; 2018. Available from: https://www.r-project.org/.

15. Tshering S. Natural Vegetable Dyes; Food, Fruit Species and Mushrooms; Gums and Waxes; and Incense. In: Non-Wood Forest Products of Bhutan. Bangkok, Thailand: Food and
Agriculture Organization of the United Nations; 1996. p. 87-106.

16. Sierra SEC, Van Welzen PC, Slik JWF. A taxonomic revision of Mallotus section Philippinenses (former section Rottlera-Euphorbiaceae) in Malesia and Thailand. Blumea. 2005;50(2):221-48. doi: 10.3767/000651905X622978.

17. Rao VS, Seshadri TR. Kamala dye as an anthelmintic. Proceedings of the Indian Academy of Sciences - Section A. 1947;26(3):178-81. doi: 10.1007/BF03170871.

18. Panda SK, Das R, Leyssen P, Neyts J, Luyten W. Assessing medicinal plants traditionally used in the Chirang Reserve Forest, Northeast India for antimicrobial activity. J Ethnopharmacol. 2018;225:220-33. doi: 10.1016/j. jep.2018.07.011.

19. Siva R. Status of natural dyes and dye-yielding plants in India. Curr Sci. 2007;92(7):916-25.

20. Maeda M, Fukami H, Namikawa K. Method for producing Mallotus philippinensis dye composition and the composition. US7556829B2, 2009.

21. Gaur RD. Traditional dye yielding plants of Uttarakhand, India. Nat Prod Radiance. 2008;7(2):154-65.

22. Caius JF. The Medicinal and Poisonous Plants of India. Jodhpur, India: Scientific Pub; 1986. p. 299-300.

23. Bhanu Prasad K, Avinash Kumar Reddy G, Joy JM, Rasheed A, Dalith D. Natural antifilarial drugs: a review. Int J Pharmacol Toxicol. 2011;1(1):1-10.

24. Srivastava MC, Singh SW, Tewari JP. Anthelmintic activity of Mallotus philippinensis-kambila powder. Indian J Med Res. 1967;55(7):746-8.

25. Gupta SS, Verma P, Hishikar K. Purgative and anthelmintic effects of Mallotus philippinensis in rats against tape worm. Indian J Physiol Pharmacol. 1984;28(1):63-6.

26. Singh R, Singhal KC, Khan NU. Antifilarial activity of Mallotus philippensis Lam. on Setaria cervie (Nematoda: Filarioidea) in vitro. Indian J Physiol Pharmacol. 1997;41(4):397-403.

27. Gangwar M, Dalai A, Chaudhary A, Singh TD, Singh SK, Goel RK, et al. Study on activity of alcoholic extract of glands and hairs of fruits of Mallotus philippinensis in murine cestodal infection model. Int J Pharm Pharm Sci. 2012;4(Suppl 1):643-5.

28. Gangwar M, Verma VC, Singh TD, Singh SK, Goel RK, Nath G. In-vitro scolicidal activity of Mallotus philippinensis (Lam.) Muell Arg. fruit glandular hair extract against hydatid cyst Echinococcus granulosus. Asian Pac J Trop Med. 2013;6(8):595-601. doi: 10.1016/s19957645(13)60103-0.

29. Jost CC, Sherman DM, Thomson EF, Hesselton RM. Kamala (Mallotus philippinensis) fruit is ineffective as an anthelminthic against gastrointestinal nematodes in goats indigenous to Balochistan, Pakistan. Small Rumin Res. 1996;20(2):147-53. doi: 10.1016/0921-4488(95)00791-1.

30. Taylor RS, Edel F, Manandhar NP, Towers GH. Antimicrobial activities of southern Nepalese medicinal plants. J Ethnopharmacol. 1996;50(2):97-102. doi: 10.1016/03788741(95)01335-0.

31. Hemachandran H, Jain F, Mohan S, Kumar DT, Priya Doss CG, Ramamoorthy S. Glandular hair constituents of Mallotus philippinensis Muell. fruit act as tyrosinase inhibitors: Insights from enzyme kinetics and simulation study. Int J Biol Macromol. 2018;107(Pt B):1675-82. doi: 10.1016/j.ijbiomac.2017.10.036.

32. Peng Z, Dongyan F, Xiaofei L. Whitening combination and 
application thereof. CN102988190B, 2012.

33. Koichi N, Hiroshi T, Kaoru S, Kazuhiko H. Hair tonic. Patent. JP3908245B2, 2004.

34. Gangwar M, Kumar D, Tilak R, Singh TD, Singh SK, Goel $\mathrm{RK}$, et al. Qualitative phytochemical characterization and antibacterial evaluation of glandular hairs covering of Mallotus phillippinensis fruit extract. J Pharm Res. 2011;4(11):4214-6.

35. Hussain T, Arshad M, Khan S, Sattar H, Qureshi MS. In vitro screening of methanol plant extracts for their antibacterial activity. Pak J Bot. 2011;43(1):531-8.

36. Bhuvaneswari R, John Xavier R, Arumugam M. Production of nanodrug for Bacillus cereus isolated from HIV positive patient using Mallotus philippensis. J Radiat Res Appl Sci. 2016;9(2):164-9. doi: 10.1016/j.jrras.2015.11.004.

37. Kumar VP, Chauhan NS, Padh H, Rajani M. Search for antibacterial and antifungal agents from selected Indian medicinal plants. J Ethnopharmacol. 2006;107(2):182-8. doi: $10.1016 /$ j.jep.2006.03.013.

38. Panda SK. Ethno-medicinal uses and screening of plants for antibacterial activity from Similipal Biosphere Reserve, Odisha, India. J Ethnopharmacol. 2014;151(1):158-75. doi: 10.1016/j.jep.2013.10.004.

39. Goud MJ, Komraiah A, Rao KN, Ragan A, Raju VS, Charya MA. Antibacterial activity of some folklore medicinal plants from South India. Afr J Tradit Complement Altern Med. 2008;5(4):421-6. doi: 10.4314/ajtcam.v5i4.31298.

40. Afzal M, Wang Z, Ali F, Song Z, Cox R, Khan S. Preliminary phytochemical screening and antimicrobial activities of various fractions of Mallotus philippensis Muell. J Med Plants Res. 2013;7(41):3066-70. doi: 10.5897/JMPR2013.5182.

41. Akhtar N, Haq IU, Mirza B. Phytochemical analysis and comprehensive evaluation of antimicrobial and antioxidant properties of 61 medicinal plant species. Arab J Chem. 2018;11(8):1223-35. doi: 10.1016/j.arabjc.2015.01.013.

42. Moorthy K, Srinivasan K, Subramanian C, Mohanasundari C, Palaniswamy M. Phytochemical screening and antibacterial evaluation of stem bark of Mallotus philippinensis var. Tomentosus. Afr J Biotechnol. 2007;6(13):1521-3. doi: 10.5897/AJB2007.000-2218.

43. Mahato RB, Chaudhary RP. Ethnomedicinal study and antibacterial activities of selected plants of Palpa district, Nepal. Sci World. 2005;3(3):26-31.

44. Nithyapriya S, Tangavelou AC, Karthikeyan S. Antimicrobial activity of glandular fruit of Mallotus philippensis. Int J Mod Res Rev. 2015;3(2):612-4.

45. Oyedemi BO, Shinde V, Shinde K, Kakalou D, Stapleton PD, Gibbons S. Novel R-plasmid conjugal transfer inhibitory and antibacterial activities of phenolic compounds from Mallotus philippensis (Lam.) Mull. Arg. J Glob Antimicrob Resist. 2016;5:15-21. doi: 10.1016/j.jgar.2016.01.011.

46. Adhav M. Phytochemical screening and antimicrobial activity of Mallotus philippensis Muell. Arg. J Pharmacogn Phytochem. 2015;3(5):188-91.

47. Rana S, Prakash V, Sagar A. Antibacterial activity of Mallotus philippensis fruit extract. J Med Plants Stud. 2016;4(3):104-6.

48. Zaidi SF, Yoshida I, Butt F, Yusuf MA, Usmanghani $\mathrm{K}$, Kadowaki $\mathrm{M}$, et al. Potent bactericidal constituents from Mallotus philippinensis against clarithromycin and metronidazole resistant strains of Japanese and Pakistani Helicobacter pylori. Biol Pharm Bull. 2009;32(4):631-6. doi: 10.1248/bpb.32.631.
49. Gupta VK, Shukla C, Bisht GR, Saikia D, Kumar S, Thakur RL. Detection of anti-tuberculosis activity in some folklore plants by radiometric BACTEC assay. Lett Appl Microbiol. 2011;52(1):33-40. doi: 10.1111/j.1472-765X.2010.02963.x.

50. Hong Q, Minter DE, Franzblau SG, Arfan M, Amin H, Reinecke MG. Anti-tuberculosis compounds from Mallotus philippinensis. Nat Prod Commun. 2010;5(2):211-7.

51. Velanganni J, Kadamban D, Tangavelou AC. Phytochemical screening and antimicrobial activity of the stem of Mallotus philippensis (Lam.) Muell. Arg. var. philippensis (Euphorbiaceae). Int J Pharm Pharm Sci. 2011;3(Suppl 2):160-3.

52. Shaikh D, Shaikh J, Rehman AB, Shafi S. Antimicrobial and toxicological studies on Mallotus philippensis (Kamala powder). Int J Pharm. 2012;2(3):613-8.

53. Harnly J. Antioxidant methods. J Food Compost Anal. 2017;64:145-6. doi: 10.1016/j.jfca.2017.08.011.

54. Sharma B, Thapa S, Bajracharya GB. Promising antioxidative potentiality and antibacterial activity of Mallotus philippensis grown in Nepal. J Pharmacogn Phytochem. 2017;6(3):629-32.

55. Khan H, Amin H, Ullah A, Saba S, Rafique J, Khan K, et al. Antioxidant and antiplasmodial activities of Bergenin and 11-O-galloylbergenin isolated from Mallotus philippensis. Oxid Med Cell Longev. 2016;2016:1-6. doi: 10.1155/2016/1051925.

56. Gangwar M, Gautam MK, Sharma AK, Tripathi YB, Goel RK, Nath G. Antioxidant capacity and radical scavenging effect of polyphenol rich Mallotus philippenensis fruit extract on human erythrocytes: an in vitro study. Sci World J. 2014;2014:279451. doi: 10.1155/2014/279451.

57. Arfan M, Amin H, Karamać M, Kosińska A, Wiczkowski W, Amarowicz R. Antioxidant activity of phenolic fractions of Mallotus philippinensis bark extract. Czech J Food Sci. 2009;27(2):109-17. doi: 10.17221/1056-CJFS.

58. Arfan M, Amin H, Karamać M, Kosińska A, Shahidi F, Wiczkowski W, et al. Antioxidant activity of extracts of Mallotus philippinensis fruit and bark. J Food Lipids. 2007;14(3):280-97. doi: 10.1111/j.1745-4522.2007.00086.x.

59. Maioli E, Greci L, Soucek K, Hyzdalova M, Pecorelli A, Fortino V, et al. Rottlerin inhibits ROS formation and prevents NFkappaB activation in MCF-7 and HT29 cells. J Biomed Biotechnol. 2009;2009:742936. doi: 10.1155/2009/742936.

60. Chhiber N, Kaur T, Singla S. Rottlerin, a polyphenolic compound from the fruits of Mallotus phillipensis (Lam.) Mull.Arg., impedes oxalate/calcium oxalate induced pathways of oxidative stress in male wistar rats. Phytomedicine. 2016;23(10):989-97. doi: 10.1016/j. phymed.2016.06.005.

61. Ramakrishna S, Geetha KM, Bhaskar gopal PVVS, Ranjit Kumar P, Charan Madav P, Umachandar L. Effect of Mallotus philippensis Muell.-Arg leaves against hepatotoxicity of Carbon tetrachloride in rats. Int J Pharma Sci Res. 2011;2(2):74-83.

62. Geetha KM. Phytochemical and Pharmacological screening of some Indian medicinal plants for antioxidant and anti-ulcer activity [thesis]. Hyderabad: Jawaharlal Nehru Technological University; 2011.

63. Gangwar M, Gautam MK, Ghildiyal S, Nath G, Goel RK. Pharmacological evaluation of Mallotus philippinensis (Lam.) Muell.-Arg. fruit hair extract for anti-inflammatory, analgesic and hypnotic activity. J Intercult Ethnopharmacol. 
2016;5(1):14-21. doi: 10.5455/jice.20151217110953.

64. Rizvi W, Fayazuddin M, Singh O, Naeem SS, Moin S, Akhtar $\mathrm{K}$, et al. Cytokine Attenuation and Free Radical Scavenging Activity of a New Flavanone7,4'-Dihydroxy-3",3"-Dimethyl -(5,6-Pyrano-2"-One)- 8- (3"',3"'-Dimethyl Allyl)- Isolated from Mallotus philippensis: Possible Mechanism for Its AntiInflammatory Activity. PLoS One. 2016;11(12):e0167294. doi: 10.1371/journal.pone.0167294.

65. Daikonya A, Katsuki S, Wu JB, Kitanaka S. Antiallergic agents from natural sources (4): anti-allergic activity of new phloroglucinol derivatives from Mallotus philippensis (Euphorbiaceae). Chem Pharm Bull (Tokyo). 2002;50(12):1566-9. doi: 10.1248/cpb.50.1566.

66. Daikonya A, Katsuki S, Kitanaka S. New phloroglucinol derivative, composition given by using the same, and antiallergenic agent. Patent. JP2003055369A, 2001.

67. Daikonya A, Katsuki S, Kitanaka S. Antiallergic agents from natural sources 9. Inhibition of nitric oxide production by novel chalcone derivatives from Mallotus philippinensis (Euphorbiaceae). Chem Pharm Bull (Tokyo). 2004;52(11):1326-9. doi: 10.1248/cpb.52.1326.

68. Chan TK, Ng DS, Cheng C, Guan SP, Koh HM, Wong WS. Anti-allergic actions of rottlerin from Mallotus philippinensis in experimental mast cell-mediated anaphylactic models. Phytomedicine. 2013;20(10):853-60. doi: $\quad 10.1016 /$ j.phymed.2013.03.012.

69. Arfan M, Amin H, Khan N, Khan I, Saeed M, Khan MA, et al. Analgesic and anti-inflammatory activities of 11-O-galloylbergenin. J Ethnopharmacol. 2010;131(2):5024. doi: $10.1016 /$ j.jep.2010.06.040.

70. Belkin M, Fitzgerald DB. Tumor-damaging capacity of plant materials. III. Plants used as pesticides. J Natl Cancer Inst. 1953;13(4):889-93. doi: 10.1093/jnci/13.4.889.

71. Sharma V. A polyphenolic compound rottlerin demonstrates significant in vitro cytotoxicity against human cancer cell lines: isolation and characterization from the fruits of Mallotus philippinensis. J Plant Biochem Biotechnol. 2011;20(2):190-5. doi: 10.1007/s13562-011-0045-6.

72. Khan M, Qureshi RA, Hussain M, Mehmood K, Khan RA. Hexane soluble extract of Mallotus philippensis (Lam.) Muell. Arg. root possesses anti-leukaemic activity. Chem Cent J. 2013;7(1):157. doi: 10.1186/1752-153x-7-157.

73. Tanaka R, Nakata T, Yamaguchi C, Wada S, Yamada T, Tokuda H. Potential anti-tumor-promoting activity of 3alpha-hydroxy-D:A-friedooleanan-2-one from the stem bark of Mallotus philippensis. Planta Med. 2008;74(4):4136. doi: 10.1055/s-2008-1034347.

74. Kulkarni RR, Tupe SG, Gample SP, Chandgude MG, Sarkar D, Deshpande MV, et al. Antifungal dimeric chalcone derivative kamalachalcone E from Mallotus philippinensis. Nat Prod Res. 2014;28(4):245-50. doi: 10.1080/14786419.2013.843178.

75. Jain SK, Pathania AS, Meena S, Sharma R, Sharma A, Singh B, et al. Semisynthesis of mallotus B from rottlerin: evaluation of cytotoxicity and apoptosis-inducing activity. J Nat Prod. 2013;76(9):1724-30. doi: 10.1021/np400433g.

76. Maioli E, Torricelli C, Valacchi G. Rottlerin and cancer: novel evidence and mechanisms. Sci World J. 2012;2012:350826. doi: 10.1100/2012/350826.

77. Soltoff SP. Rottlerin: an inappropriate and ineffective inhibitor of PKCdelta. Trends Pharmacol Sci. 2007;28(9):453-8. doi: 10.1016/j.tips.2007.07.003.

78. Park EJ, Kwon TK. Rottlerin enhances IL-1beta-induced
COX-2 expression through sustained p38 MAPK activation in MDA-MB-231 human breast cancer cells. Exp Mol Med. 2011;43(12):669-75. doi: 10.3858/emm.2011.43.12.077.

79. Kumar D, Shankar S, Srivastava RK. Rottlerin induces autophagy and apoptosis in prostate cancer stem cells via PI3K/Akt/mTOR signaling pathway. Cancer Lett. 2014;343(2):179-89. doi: 10.1016/j.canlet.2013.10.003.

80. Wang L, Hou Y, Yin X, Su J, Zhao Z, Ye X, et al. Rottlerin inhibits cell growth and invasion via down-regulation of Cdc20 in glioma cells. Oncotarget. 2016;7(43):69770-82. doi: 10.18632 /oncotarget.11974.

81. Su J, Wang L, Yin X, Zhao Z, Hou Y, Ye X, et al. Rottlerin exhibits anti-cancer effect through inactivation of $S$ phase kinase-associated protein 2 in pancreatic cancer cells. Am J Cancer Res. 2016;6(10):2178-91.

82. Fu LM, Fu-Liu CS. Is Mycobacterium tuberculosis a closer relative to Gram-positive or Gram-negative bacterial pathogens? Tuberculosis (Edinb). 2002;82(2-3):85-90. doi: 10.1054/tube.2002.0328.

83. Gupta VK, Kaushik A, Chauhan DS, Ahirwar RK, Sharma S, Bisht D. Anti-mycobacterial activity of some medicinal plants used traditionally by tribes from Madhya Pradesh, India for treating tuberculosis related symptoms. J Ethnopharmacol. 2018;227:113-20. doi: 10.1016/j. jep.2018.08.031.

84. Furumoto T, Ozawa N, Inami Y, Toyoshima M, Fujita $\mathrm{K}$, Zaiki K, et al. Mallotus philippinensis bark extracts promote preferential migration of mesenchymal stem cells and improve wound healing in mice. Phytomedicine. 2014;21(3):247-53. doi: 10.1016/j.phymed.2013.09.003.

85. Kitamura K, Inami Y, Nakaoji K, Hamada K, Maeda A, Furumoto T, et al. Mesenchymal stem cell attractant and method for attracting mesenchymal stem cell. Patent. US9458429B2, 2016.

86. Gangwar M, Gautam MK, Ghildiyal S, Nath G, Goel RK. Mallotus philippinensis Muell. Arg fruit glandular hairs extract promotes wound healing on different wound model in rats. BMC Complement Altern Med. 2015;15:123. doi: 10.1186/s12906-015-0647-y.

87. Afzal M, Zhang L, Cox RJ, Muhammad N, Khan S. Isolation of two new mallotoates with antifungal and radical scavenging activities from Mallotus phillipensis Muell. Asian J Chem. 2015;27(10):3891-4. doi: 10.14233/ ajchem.2015.19047.

88. Ietta F, Maioli E, Daveri E, Gonzaga Oliveira J, da Silva RJ, Romagnoli R, et al. Rottlerin-mediated inhibition of Toxoplasma gondii growth in BeWo trophoblast-like cells. Sci Rep. 2017;7(1):1279. doi: 10.1038/s41598-017-01525-6.

89. Shivshankar P, Lei L, Wang J, Zhong G. Rottlerin inhibits chlamydial intracellular growth and blocks chlamydial acquisition of sphingolipids from host cells. Appl Environ Microbiol. 2008;74(4):1243-9. doi: 10.1128/aem.02151-07.

90. Gillespie RS, Stapleton FB. Nephrolithiasis in children. Pediatr Rev. 2004;25(4):131-9. doi: 10.1542/pir.25-4-131.

91. Mohandas S, Nizar S, PV R. Evaluation of in vitro antiurolithiatic activity of Vidangadi Churna. World J Pharm Pharm Sci. 2015;4(10):800-7.

92. Taylor RS, Hudson JB, Manandhar NP, Towers GH. Antiviral activities of medicinal plants of southern Nepal. J Ethnopharmacol. 1996;53(2):97-104. doi: 10.1016/03788741(96)01430-4.

93. Gujral ML, Varma DR, Sareen KN. Oral contraceptives. Part I. Preliminary observations on the antifertility effect of 
some indigenous drugs. Indian J Med Res. 1960;48:46-51.

94. Gujral ML, Varma DR, Sareen KN, Roy AK. Oral contraceptives. Part II. Antifertility effect of Mallotus philippinensis Mueller-argoviensis. Indian J Med Res. 1960;48:52-8.

95. Thakur SC, Thakur SS, Chaube SK, Singh SP. An etheral extract of Kamala (Mallotus philippinensis (Moll.Arg) Lam.) seed induce adverse effects on reproductive parameters of female rats. Reprod Toxicol. 2005;20(1):149-56. doi: 10.1016/j.reprotox.2004.12.008.

96. Akhtar MS, Ahmad I. Comparative efficacy of Mallotus philippinensis fruit (Kamala) or Nilzan ${ }^{\bullet}$ drug against gastrointestinal cestodes in Beetal goats. Small Rumin Res. 1992;8(1-2):121-8. doi: 10.1016/0921-4488(92)90013-T.

97. Kulakkattolickal AT. Piscicidal plants of nepal: preliminary toxicity screening using grass carp (Ctenopharyngodon idella) fingerlings. J Ethnopharmacol. 1987;21(1):1-9. doi: 10.1016/0378-8741(87)90088-2.

98. Bist A, Kumar L, Roy I, Ravindran P, Gaurs SN, Singh AB. Clinico-immunologic evaluation of allergy to Himalayan tree pollen in atopic subjects in India--a new record. Asian Pac J Allergy Immunol. 2005;23(2-3):69-78.

99. Rawat A, Singh A, Roy I, Kumar L, Gaur SN, Ravindran P, et al. Assessment of allergenicity to Mallotus phillipensis pollen in atopic patients in India: a new allergen. J Investig Allergol Clin Immunol. 2004;14(3):198-207.

100. Aggarwal JS, Sharma VN, Gupta SC. Manufacture of useful compounds and products from the seed oil of Mallotus philippinensis Muell. Arg. US2685593A, 1954.

101. Smith MA, Zhang H, Forseille L, Purves RW. Characterization of novel triacylglycerol estolides from the seed oil of Mallotus philippensis and Trewia nudiflora. Lipids. 2013;48(1):75-85. doi: 10.1007/s11745-012-3721-y.

102. Gupta SC, Gupta SS, Aggarwal JS. The component acids of kamala oil (Mallotus Philippinensis, Muell. Arg.). J Am Oil Chem Soc. 1954;31(7):287-9. doi: 10.1007/BF02639158.

103. Roberts KD, Weiss E, Reichstein T. Die Cardenolide der Samen von Mallotus philippinensis (LAM.) MÜLL.-ARG. (= Rottlera tinctoria ROXB.). Glykoside und Aglykone, 252. Mitteilung. Helv Chim Acta. 1963;46(7):2886-93. doi: 10.1002/hlca.19630460745.

104. Bandopadhyay M, Dhingra VK, Mukerjee SK, Pardeshi
NP, Seshadri TR. Triterpenoid and other components of Mallotus philippinensis. Phytochemistry. 1972;11(4):1511.

105. Nair SP, Madhusudana Rao J. Kamaladiol-3-acetate from the stem bark of Mallotus philippinensis. Phytochemistry. 1993;32(2):407-9. doi: 10.1016/S0031-9422(00)95004-0.

106. Saijo R, Nonaka G, Nishioka I. Tannins and related compounds. LXXXIV. Isolation and characterization of five new hydrolyzable tannins from the bark of Mallotus japonicus. Chem Pharm Bull (Tokyo). 1989;37(8):2063-70. doi: $10.1248 / \mathrm{cpb} .37 .2063$.

107. Tanaka T, Ito T, Iinuma $M$, Takahashi $Y$, Naganawa $H$. Dimeric chalcone derivatives from Mallotus philippensis. Phytochemistry. 1998;48(8):1423-7. doi: 10.1016/S00319422(98)00131-9.

108. Furusawa M, Ido Y, Tanaka T, Ito T, Nakaya KI, Ibrahim I, et al. Novel, complex flavonoids from Mallotus philippensis (Kamala tree). Helv Chim Acta. 2005;88(5):1048-58. doi: 10.1002/hlca.200590076.

109. Li Y, Luo Y, Huang W, Wang J, Lu W. Total synthesis of mallotophilippen C. Tetrahedron Lett. 2006;47(25):4153-5. doi: 10.1016/j.tetlet.2006.04.064.

110. Mai NT, Cuong NX, Thao NP, Nam NH, Khoi NH, Minh $\mathrm{CV}$, et al. A new lignan dimer from Mallotus philippensis. Nat Prod Commun. 2010;5(3):423-6.

111. Crombie L, Green CL, Tuck B, Whiting DA. Constituents of kamala. Isolation and structure of two new components. J Chem Soc C Org. 1968;0(0):2625-30. doi: 10.1039/ J39680002625.

112. Lounasmaa M, Widén CJ, Tuuf CM, Huhtikangas A. On the phloroglucinol derivatives of Mallotus philippinensis. Planta Med. 1975;28(1):16-31. doi: 10.1055/s-0028-1097825.

113. Lee YR, Li X, Kim JH. Concise total synthesis of biologically interesting mallotophilippens $\mathrm{C}$ and e. J Org Chem. 2008;73(11):4313-6. doi: 10.1021/jo800367r.

114. Xia L, Lee YR. Efficient synthesis of biologically interesting natural pyranochalcones from Mallotus philippensis and their unnatural derivatives. Bull Korean Chem Soc. 2011;32(spc8):2921-7. doi: 10.5012/bkcs.2011.32.8.2921.

115. Li Y, Yu B, Wang R. Efficient synthesis of rottlerin and its two subunits. Tetrahedron Lett. 2016;57(17):1856-9. doi: 10.1016/j.tetlet.2016.03.049. 